NBSIR 86-3499 [USAF]

\title{
The Effect of Volatile Organic Compound Regulations on the Selection and Use of Coatings Included in AFM 85-3 (Tri-Service Paints and Protective Coatings Manual)
}

Mary E. McKnight

U.S. DEPARTMENT OF COMMERCE

National Bureau of Standards

National Engineering Laboratory

Center for Building Technology

Building Materials Division

Gaithersburg, MD 20899

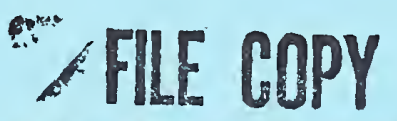

DO MOT REMOUE

December 1986

Issued February 1987

Sponsored by

Air Force Engineering and Services Center

Tyndall Air Force Base, FL 32403

Purchase Order No. F86-50 

THE EFFECT OF VOLATILE ORGANIC COMPOUND REGULATIONS ON THE SELECTION AND USE OF COATINGS INCLUDED IN AFM 85-3 (TRI-SERVICE PAINTS AND PROTECTIVE COATINGS MANUAL)

Mary E. McKnight

\section{U.S. DEPARTMENT OF COMMERCE}

National Bureau of Standards

National Engineering Laboratory

Center for Building Technology

Building Materials Division

Gaithersburg, MD 20899

December 1986

Issued February 1987

Sponsored by

Air Force Engineering and Services Center

Tyndall Air Force Base, FL 32403

Purchase Order No. F86-50

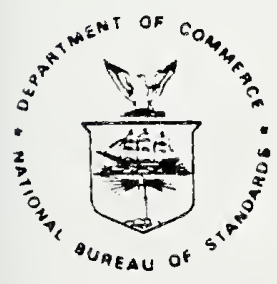

U.S. DEPARTMENT OF COMMERCE, Malcolm Baldrige, Secretary NATIONAL BUREAU OF STANDARDS, Ernest Ambler, Director 



\section{ABSTRACT}

The potential impact of the Federal Clean Air Act upon coating specifications recommended in AFM 85-3, Tri-Service Paints and Protective Coatings Manual, for the maintenance of Air Force Facilities is assessed. The volatile organic content of each paint and recommendations of the coordinating activity are listed. Substitute coating specifications are recommended for noncompliant ones when possible.

Keywords: Coating, paints, volatile organic compound, Tri-Service Paints and Protective Coatings Manual, AFM 85-3 
This report was sponsored by the Air Force Engineering and Services Center, Tynda11 Air Force Base, Florida. Technical coordination with the Air Force Engineering and Services Center was provided by $\mathrm{Mr}$. Jesse Neal whose assistance and encouragement are gratefully acknowledged. 
ACKNOWLEDGEMENT . . . . . . . . . . . . . . . . . . IV

TABLE OF CONTENTS . . . . . . . . . . . . . . . . . . . . . . V v

LIST OF TABLES . . . . . . . . . . . . . . . . . . . . vi

1. INTRODUCTION . . . . . . . . . . . . . . . . . . . . 1

1.1 Background . . . . . . . . . . . . . . . . . . . . . . 1

1.2 Objectives and Scope ............... 2

2. STATUS OF COATING SPECIFICATIONS IN MANUAL ............. 3

2.1 Rules Governing VOC of Coatings . . . . . . . . . . . . . . . . 3

2.1 .1 Background ................ . . 3

2.1.2 Rule Requirements . . . . . . . . . . . . . . . . 6

2.2 VOC of Coatings in AFM 85-3 ............ . . 7

2.3 Selection Tables in Manual Showing SCAQMD Non-Compliant Coatings. . 12

2.4 Proposed Replacements for Non-Compliant Coatings. . . . . . . . . 12

3. RECOMMENDATIONS . . . . . . . . . . . . . . . . . . 14

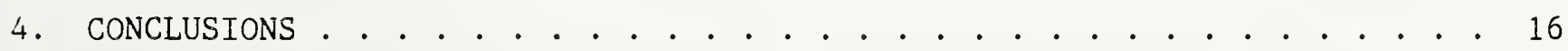

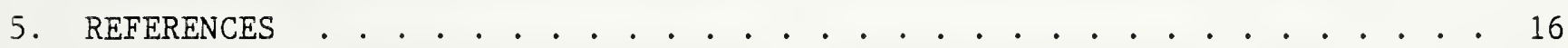

Appendix A. California South Coast Air Quality Management District Architectural Coatings Rule 1113 and Coating of Metal Parts and Products Rule 1107.............. . A-1

Appendix B. Summary of AFM 85-3 Coating Recommendations Affected by SCAQMD Rule 1113 . . . . . . . . . . . . . . B-1

Appendix C. Suggested Replacements for Non-Compliant Coatings Recommended in AFM 85-3...................... C-1 


\section{LIST OF TABLES}

Page

Table 1. VOC of Coatings Specifications Used in Tri-Service Paints and Protective Coatings Manual 
I. INTRODUCTION

\subsection{Background}

Selection and use of coating systems for maintenance of facilities are subject to many constraints, including federal and local environmental regulations. Recormendations regarding selection and use should help users choose proper systems that are in compliance with all regulations. Recent and upcoming changes in environmental regulations associated with the Clean Air Act may bring about major changes in government coating specifications and consequently in recommended coating systems for maintenance of facilities.

The Clean Air Act of 1970, amended in 1977, gives the Environmenta1 Protection Agency (EPA) the responsibility for establishing air quality standards for pollutants that may harm the public health and welfare. EPA has set national ambient air quality standards for six major pollutants. The pollutant of interest in this discussion is ozone, since ozone concentration in the air is directly related to the presence of organic materials in the air, including those produced by the drying and curing of coatings [1]. According to the law, the entire country must meet the requirements of the Clean Air Act, including the ozone leve1, by December 31, 1987. Currently, about 10 percent of U.S. counties have not attained the standard for ozone, and those counties contain virtually all of the major U.S. urban areas [2]. Thus, both federal and local environmental agencies are stepping-up enforcement of regulations involving emission of organic materials, including those from coatings, and are considering additional regulations that may lower the allowable content of volatile 
organic compounds (VOC) of coatings. These actions have resulted in the need for review and possible revision of federal government coating specifications.

\subsection{Objectives and Scope}

This report was prepared at the request of the Air Force Engineering and Services Center to help assess the impact of VOC regulations on the selection and use of coatings recommended for maintenance of facilities as given in the TriService Paints and Protective Coatings Manual (AFM 85-3) [3]. The objectives of the report are to 1) list the VOC content of all coatings recommended in AFM $85-3,2)$ divide the coatings into groups according to compliance with the more restrictive controlling regulations, such as California's South Coast Air Quality Management District's Architectural Rule 1113, and their Coating of Metal Parts and Products Rule 1107, 3) suggest alternatives, to the extent possible, for the non-compliant coatings, and 4) list generic types of materials for which purchasing documents are needed. This report will not discuss compliance with other regulations that also may affect some government coating operations.

This report is intended to give guidance for the selection and use of compliant coatings. However, it must be noted that there are many regulations, both local and federal, governing the VOC of coatings and that they vary from regj to region within the country. Thus, when there is doubt about the compiiance of a material for a specific use, local environmentalists should be consulted. 
This review of government coating specifications for compliance with California rules also provides a unique opportunity to increase our understanding of the needs of users for performance data, as well as selection and use criteria for new materials.

2. STATUS OF COATING SPECIFICATIONS IN MANUAL

\subsection{Rules Governing VOC of Coatings}

\subsubsection{Background}

Before discussing specific rules governing volatile organic compounds (VOC) of coatings, a little history on the development of the rules is presented to aid in the understanding of their effect on government coating specifications. As a result of the Clean Air Act as amended in 1977 , EPA required all states in non-attainment of the ozone limit of the National Ambient Air Quality Standards to revise their State Implementation Plans for control of ozone. To help the states with their plans for lowering the VOC of coatings, EPA published a series of Control Techniques Guideline (CTG) documents containing EPA's recommendations for control of eleven specific end-use surface coating operations and VOC of related materials [4]. The eleven end-use coating categories addressed by CTGs include automotive and light-duty trucks, can, coil, metal furniture, large appliance, fabric, paper, magnetic wire, metal parts and products, flatwood paneling, and graphic arts. Thirty-five states, or portions thereof (called regions in this report), adopted coating regulations, based on these recommendations. These regulations affect some DoD coating operations, such as 
those involving airplanes, mobile equipment and, to some extent, ships. In addition to these eleven end-uses, some regions of California also control the VOC of architectural coatings, including those used for coating maintenance of facilities. Currently, no other regions in the country control the VOC of architectural coatings. However, other regions of the country are considering control of VOC of architectural coatings and EPA has proposed consideration of a CTG for architectural coatings [5].

To help establish the extent of the problem regarding compliance of government specification coatings with environmental regulations, the Department of Defense through the Office of the Secretary of Defense, tasked Fort Belvoir's Research, Development and Engineering Center with developing information on the compliance status of each specification coating included in the Federal Supply Schedule, FSC 8010 [6]. Work in this task included determining the VOC of each coating defined by a federal specification and recommending action for each specification which does not comply. To meet the requirements of the task, the Fort Belvoir Center requested each government activity responsible for coordinating government coating specifications to report to the Center the following information for each specification: 1) document number, 2) document title, 3) VOC, 4) coating type and use, 5) will it be cancelled, 6) will it be designated for revision, 6) and proposed action to reduce VOC content.

Since compliance of a coating depends both upon the region of the country in which the coating is used and the end-use, the most restrictive rules were used as a measure of compliance by the Fort Belvoir Center, reasoning that if a coating were compliant with the most restrictive rules, it would be compliant for use 
in any region. Since California's rules are considered to be the most restrictive of al1 U.S. rules, this resulted in the use of its rules as the measure of compliance. In most instances, the Fort Belvoir Center used the South Coast Air Quality Management District's (SCAQMD) Coating of Metal Parts and Products Rule 1107 as the measure of compliance. In some cases, the specification coordinating activity used the SCAQMD's Architectural Coatings Rule 1113 as a measure of compliance [6].

A similar measure of compliance was used in this report since one of the recommendations for the Office of the Secretary of Defense [6] was that all federal specifications should comply with the most restrictive environmental rules. The most restrictive rules applicable to facility maintenance painting appear to be the SCAQMD Rules for metal parts and products (Rule 1107) and architectural coatings (Rule 1113) and they are used as a measure of compliance in this report. Copies of these rules, Architectural Coatings Rule 1113 and Coating of Metal Parts and Products Rule 1107, are reproduced in Appendix A to this report.

In addition to the diversity of the rules that may apply to coating operations, rules are often somewhat difficult for coating users to interpret. For example, in SCAQMD's Architectural Coating Rule there are two general categories of coatings: architectural coatings and architectural specialty coatings. Neither category is defined specifically in the rule. From conversations with people representing industry ${ }^{1}$ and the government ${ }^{2}$, it appears that the usual

${ }^{1}$ Personal conversation with Raymond Connor, National Paint and Coatings Association, October 1986. 
interpretation of the rule is that architectural coatings are those generally thought of as trade-sales by the industry (with the exception of varnishes, lacquers, and stains) and specialty architectural coatings are all other architectural coatings. In addition, some coating types, such as vinyl. lacquers, could fall under more than one classification within the rule, each having a different VOC limit.

\subsubsection{Rule Requirements}

The VOC requirements of SCAQMD Rules 1113 and 1107 are listed below. The SCAQMD's Architectural Rule 1113 requires, for flat coatings, a VOC of less than or equal 250 grams/liter $(g / 1)$ ( 2.1 pounds/gal), excluding water and any colorant added to tint bases. The present SCAQMD Architectural Rule linit for non-flat coatings is $380 \mathrm{~g} / \mathrm{l}$ ( 3.2 pounds/gal). According to the rule as amended Nov. 1, 1985, this limit for non-flat coatings will be changed to 250 g/1 September 2, 1989. However, EPA, Region 9, has informed SCAQMD that they intend to publish a notice of disapproval of this amendment ${ }^{3}$. If such a notice is issued, the allowable VOC limit for non-flat coatings would be decreased to $250 \mathrm{~g} / \mathrm{l}$ at an earlier date than September 2, 1989. EPA rulings would appear in the Federal Register.

For specialty coatings, the VOC limits of SCAQMD's Architectural Coating Rule 1113 vary depending upon the type (both generic and functional) of the

2 Personal conversation with S. Dobrin, SCAQMD, November 1986.

3 Personal conversation with Raymond Connor, National Paint and Coatings Association, October, 1986. 
coating. Effective September 1, 1987, a maximum VOC will apply to each type of coating. At that time, most industrial maintenance-type coatings will have a VOC limit of $420 \mathrm{~g} / 1$ ( 3.5 pounds/gal). Other limits will range from $250 \mathrm{~g} / 1$ (2.08 pounds/gal) for traffic paints to $680 \mathrm{~g} / 1$ ( 5.67 pounds/gal) for lacquers.

The VOC limits for coatings used under the SCAQMD's Coating of Metal Parts and Products Rule 1107 are $340 \mathrm{~g} / 1$ (2.8 pounds/gal) for air-dry coatings and $275 \mathrm{~g} / 1$ ( 2.3 pounds/gal) for baked coatings.

\subsection{VOC of Coatings in AFM 85-3}

With the exception of a few specifications (marked with a "*"), the VOC of coatings recommended for use in the Tri-Service Paints and Protective Coatings Manual, AFM 85-3, was obtained from a draft report prepared by Fort Belvoir's Research, Development and Engineering Center for the Office of the Secretary of Defense [6]. For specifications marked with a "*", the VOC was calculated using weight requirements of the specification. Along with the VOC of each coating, the recommendations and comments of the coordinating activities concerning the specification as stated in the Fort Belvoir report are listed in Table 1. Action on these recommendations by user activities has not been taken as of December 1, 1986. (Materials recommended for use in the Manual [3] not covered by the rules, such as putties, resins, etc. are not included in the table.) 
Table 1. VOC of Coating Specifications Used in Tri-Service Paints and Protective Coatings Manual

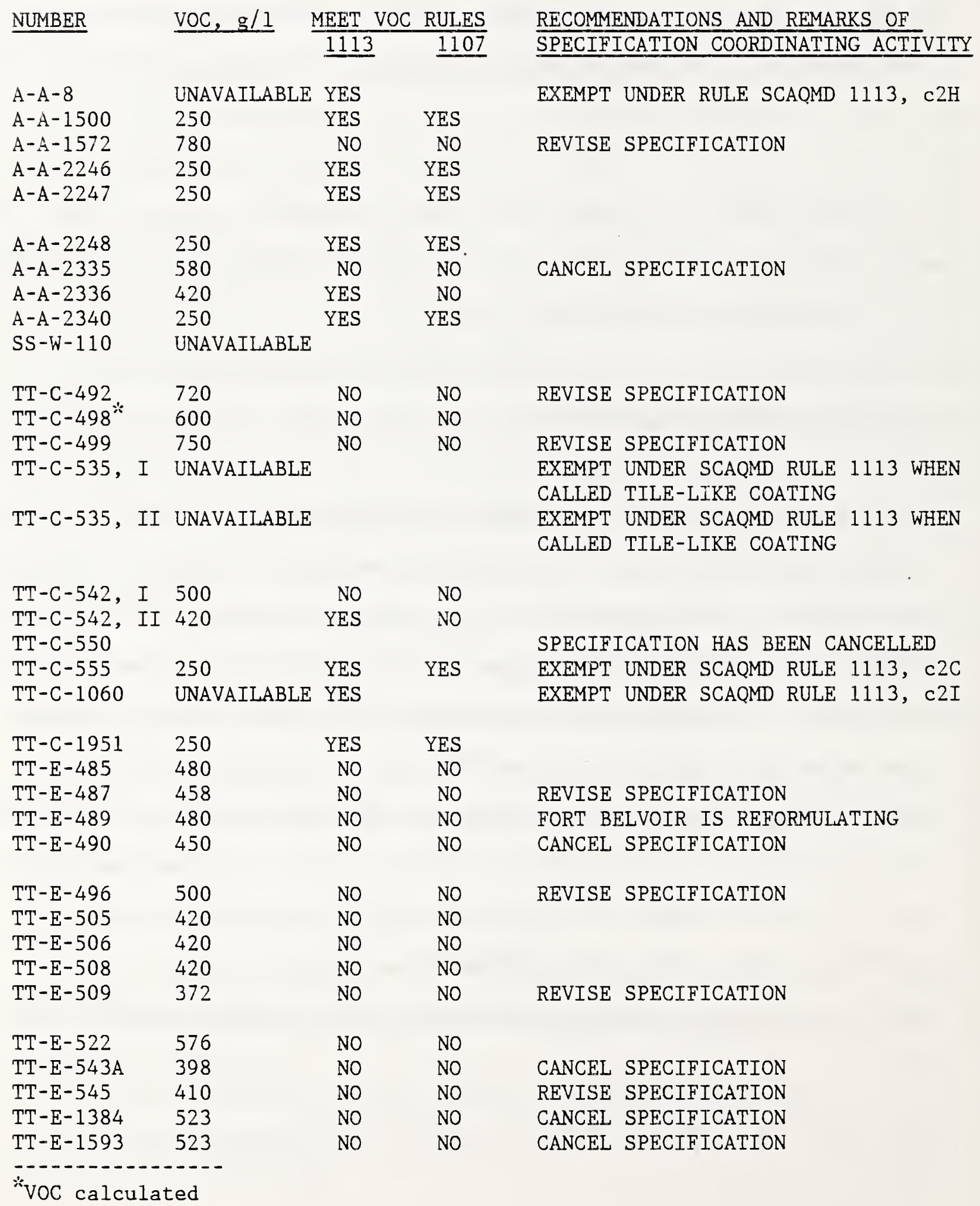


Table 1 Cont. VOC of Coating Specifications in Tri-Service Paints and Protective Coatings Manual

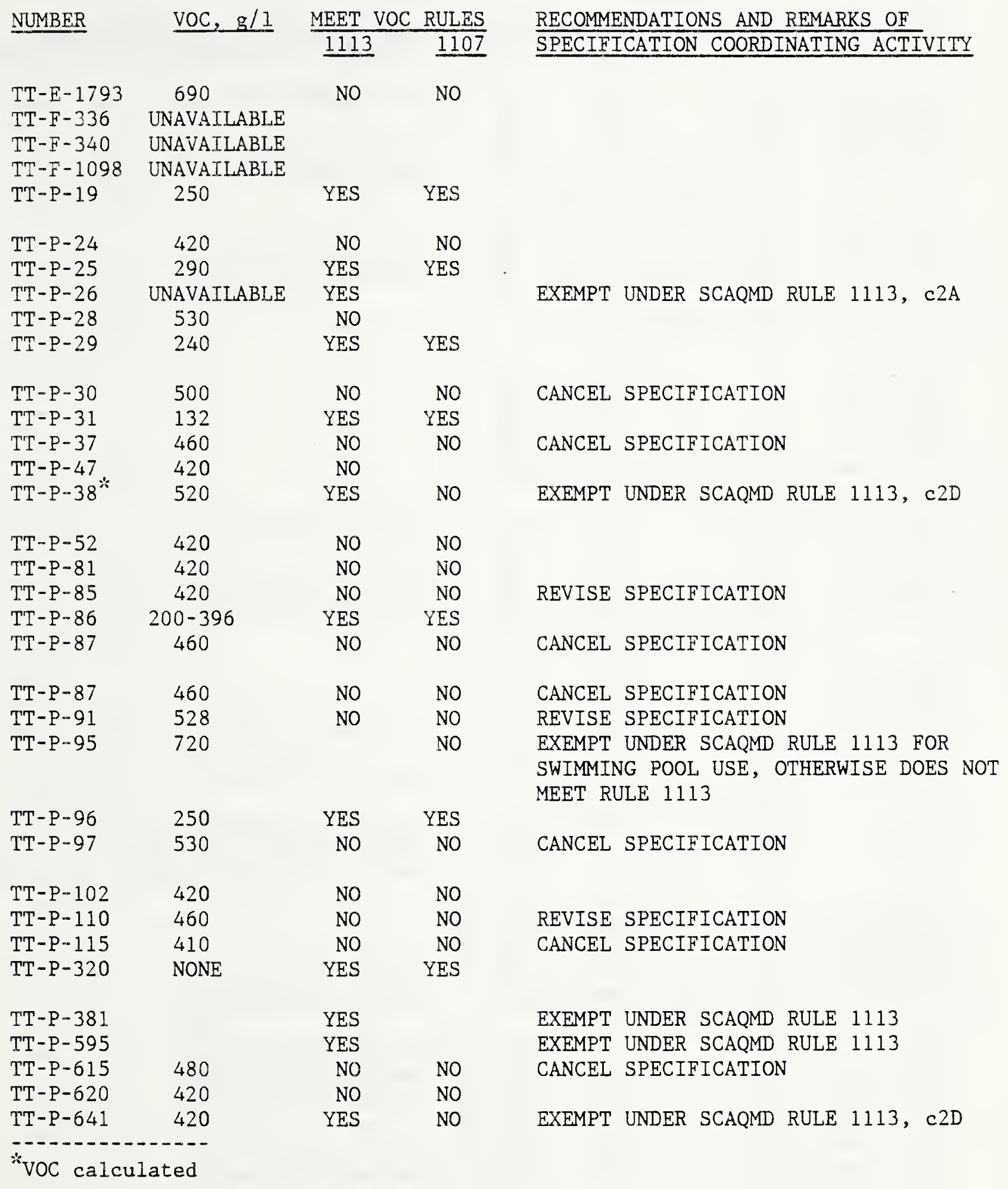


Table 1 Cont. VOC of Coating Specifications in Tri-Service Paints and Protective Coatings Manual

\begin{tabular}{|c|c|c|c|c|}
\hline NUMBER & VOC, $g / 1$ & $\frac{\text { MEET VOC }}{1113}$ & $\frac{\text { RULES }}{\underline{1107}}$ & $\begin{array}{l}\text { RECOMMENDATIONS AND REMARKS OF } \\
\text { SPECIEICATION COORDINATING ACTIVITY }\end{array}$ \\
\hline $\mathrm{TT}-\mathrm{P}-645$ & 444 & NO & NO & REVISE SPECIFICATION \\
\hline $\mathrm{TT}-\mathrm{P}-650$ & 250 & YES & YES & \\
\hline TT-P-659 & 480 & NO & NO & CANCEL SPECIFICATION \\
\hline $\mathrm{TT}-\mathrm{P}-1046$ & 520 & YES & NO & EXEMPT UNDER SCAQMD RULE 1113, d2D \\
\hline $\mathrm{TT}-\mathrm{P}-1181^{*}$ & 480 & NO & NO & \\
\hline $\mathrm{TT}-\mathrm{P}-1385$ & 450 & NO & NO & CANCEL SPECIFICATION \\
\hline $\mathrm{TT}-\mathrm{P}-1411$ & 460 & NO & NO & CANCEL SPECIFICATION \\
\hline $\mathrm{TT}-\mathrm{P}-1510$ & 250 & YES & YES & \\
\hline $\mathrm{TT}-\mathrm{P}-1511$ & 250 & YES & & \\
\hline $\mathrm{TT}-\mathrm{P}-1565$ & 380 & YES & NO & \\
\hline $\mathrm{TT}-\mathrm{P}-1728$ & 250 & YES & YES & \\
\hline $\mathrm{TT}-\mathrm{P}-1757^{*}$ & 490 & NO & NO & \\
\hline $\mathrm{TT}-\mathrm{P}-1952$ & 250 & YES & YES & \\
\hline $\mathrm{TT}-\mathrm{P}-1984$ & 250 & YES & YES & \\
\hline $\mathrm{TT}-\mathrm{P}-2118$ & VARIES & NO & NO & CANCEL SPECIFICATION \\
\hline $\mathrm{TT}-\mathrm{P}-2119$ & 250 & YES & YES & \\
\hline TT-S-176 & 520 & NO & NO & CANCEL SPECIFICATION \\
\hline TT-S- 179 & 486 & NO & NO & REVISE SPECIFICATION \\
\hline TT-S- 190 & 690 & NO & NO & \\
\hline TT-S-223 & 336 & YES & YES & \\
\hline TT-S-708 & 420 & NO & NO & \\
\hline $\mathrm{TT}-\mathrm{S}-711$ & 690 & NO & No & \\
\hline TT-S- 1992 & 250 & YES & YES & \\
\hline $\mathrm{TT}-\mathrm{V}-51$ & 530 & NO & NO & CANCEL SPECIFICATION \\
\hline $\mathrm{TT}-\mathrm{V}-71$ & 478 & NO & NO & CANCEL SPECIFICATION \\
\hline $\mathrm{TT}-\mathrm{V}-81$ & $>430$ & & NO & $\begin{array}{l}\text { EXEMPT UNDER SCAQMD RULE } 1113, \text { c2D } \\
\text { FOR USE AS MIXING VARNISH FOR AL PIGMENT }\end{array}$ \\
\hline $\mathrm{TT}-\mathrm{V}-85$ & 690 & NO & NO & \\
\hline $\mathrm{TT}-\mathrm{V}-86$ & 490 & NO & NO & \\
\hline $\mathrm{TT}-\mathrm{V}-109$ & 370 & NO & NO & \\
\hline TT-V-119 & 370 & NO & NO & REVISE SPECIFICATION \\
\hline $\mathrm{TT}-\mathrm{V}-121$ & 410 & NO & NO & CANCEL SPECIFICATION \\
\hline DOD-E-698 & 445 & NO & NO & CANCEL SPECIFICATION \\
\hline DOD-E-699 & 415 & YES & NO & CANCEL SPECIFICATION \\
\hline DOD-E-700 & 450 & No & NO & CANCEL SPECIFICATION \\
\hline MIL-C-4556, & 530,576 & NO & NO & \\
\hline MIL-C $-5044^{*}$ & 480 & NO & No & \\
\hline MIL-S-12935* & $* 660$ & NO & NO & CANCEL SPECIFICATION \\
\hline
\end{tabular}


Table 1 Cont. VOC of Coating Specifications in Tri-Service Paints and Protective Coatings Manual

\begin{tabular}{|c|c|c|c|c|}
\hline NUMBER & VOC, $g / 1$ & $\frac{\text { MEET VOC }}{1113}$ & $\frac{\text { RULES }}{\underline{1107}}$ & $\frac{\text { RECOMMENDATIONS OF SPECIFICATION }}{\text { COORDINATING ACTIVITY }}$ \\
\hline MIL-P-14105\% & 400 & YES & NO & \\
\hline MIL-E-15145* & 510 & NO & NO & \\
\hline MIL-C-15203 & UNAVAILABLE & & & \\
\hline DOD-C- 15328 & 760 & NO & NO & CANCEL SPECIFICATION \\
\hline MIL-P-15930 & 700 & NO & NC & CANCEL SPECIFICATION \\
\hline MIL-E-18210 & 434 & NO & NO & CANCEL SPECIFICATION \\
\hline MIL-E-18214 & 420 & YES & NO & CANCEL SPECIFICATION \\
\hline MIL-C- 18480 & UNAVAILABLE & & & \\
\hline MIL-P-20090 & 430 & NO & NO & CANCEL SPECIFICATION \\
\hline MIL-C-22750 & 552 & NO & NO & \\
\hline MIL-P-23377 & 552 & NO & NO & TYPES 1 and 2 \\
\hline MIL-P-23377 & 350 & YES & YES & TYPE 3 \\
\hline MIL-P-24351 & 445 & NO & NO & REVISE SPECIFICATION \\
\hline MIL-P-24441 & $<420$ & YES & NO & MIN ALLOWED SOLVENT IN ALL \\
\hline MIL-P-26915 & 540 & YES & NO & EXEMPT UNDER RULE $1113, \mathrm{c} 2 \mathrm{D}$ \\
\hline MIL $-\mathrm{P}-28577$ & 250 & YES & YES & \\
\hline MIL-P-28578 & 250 & YES & YES & \\
\hline MIL-P-28582 & 445 & NO & NO & REVISE SPECIFICATION \\
\hline MIL-P-28641 & 710 & NO & NO & REVISE SPECIFICATION \\
\hline MIL-P-28642 & 710 & NO & NO & REVISE SPECIFICATION \\
\hline MIL-R-46073 & REMOVER & & & \\
\hline MIL-C-46081 & THERMAL INS & SULATING & & \\
\hline MIL-P-52192 & UNAVAILABLE & & & \\
\hline MIL-P- 52324 & & & & SPECIFICATION HAS BEEN CANCELLED \\
\hline MIL-C-81346 & 470 & NO & NO & REVISE SPECIFICATION \\
\hline MIL-C-83286 & 575 & NO & NO & REVISE SPECIFICATION \\
\hline VR $-3 *$ & 660 & NO & NO & \\
\hline VR $-6 *$ & 660 & NO & NO & \\
\hline SSPC $-1 *$ & 48 & YES & YES & VOC CALCULATED FROM SPECIFICATION \\
\hline SSPC $-2 *$ & 504 & NO & NO & VOC CALCULATED FROM SPECIFICATION \\
\hline SSPC $-5^{*}$ & 350 & YES & No & VOC CALCULATED FROM SPECIFICATION \\
\hline & & & & EXEMPT UNDER SCAQMD RULE 1113 , C2D \\
\hline $\operatorname{SSPC}-8^{*}$ & 720 & YES & NO & EXEMPT UNDER SCAQMD RULE 1113 , c2D \\
\hline SSPC $-11 *$ & 275 & YES & YES & \\
\hline $\mathrm{SSPC}-9 \%$ & 685 & NO & NO & \\
\hline SSPC $-15 \%$ & 530 & NO & NO & \\
\hline SSPC- $16^{*}$ & $540-770$ & NO & NO & \\
\hline SSPC- $18^{*}$ & 745 & NO & NO & \\
\hline SSPC $-21 *$ & $395-480$ & NO & NO & \\
\hline SSPC $-25 *$ & 384 & YES & NO & \\
\hline $\operatorname{SSPC}-27 *$ & 760 & NO & NO & \\
\hline
\end{tabular}




\subsection{Selection Tables in Manual Showing SCAQMD Non-compliant Coatings}

A summary of the coating specifications affected by the proposed changes in the specifications to meet SCAQMD Rules 1113 and 1107 are shown in Appendix B to this report. This summary was done using copies of the tables as they appear in Appendix D of AFM 85-3. All potentially affected specifications are enclosed in a box. The tables were not re-typed so that proposed changes in specifications upon the selection of coating systems could be easily noted. The legend for the "mark-up" of the tables is shown on each of the selection tables.

\subsection{Proposed Replacements for Non-Compliant Coatings}

A summary of the proposed replacement coating specifications for those that are not compliant with SCAQMD Rule 1113 is shown in Appendix C to this report. As for Appendix B, Appendix C follows the format of the selection tables in AFM 85-3. As can be noted, there are situations in which either replacement materials available are not available or only limited performance data is available for replacement materials that are defined by government specifications. Needs for additional performance criteria and government purchasing documents include:

- clear finishes (industry is having trouble supplying)

- stains for wood (industry is having trouble supplying organic-solvent based) 
- latex coatings (commercial materials are available)

$$
\begin{aligned}
& \text { interior: semigloss and gloss in mid-and deep tones } \\
& \text { exterior: semigloss and gloss in mid-and deep tones, } \\
& \text { flat in mid- and deep tones }
\end{aligned}
$$

- high solids epoxies (commercial materials are available, but need evaluation; Navy is working on a government specification)

- high solids urethane finish coat (commercial materials are available, but need evaluation)

- replacement for vinyls and rubbers for concrete/masonry in corrosive and wet environments (industry is having trouble supplying)

- replacement for wash primer (difficult to formulate replacement as presently supplied)

- high solids alkyds or other easy-to-recoat type of coating (industry is having trouble supplying)

- high solids coating for use on marginally prepared steel, such as epoxy mastics, to replace TT-P-645 (epoxy mastics are commercially available, but need evaluation; Navy is working on VOC compliant TT-P-645)

- improved latex maintenance systems for steel (commercial materials are available, but need evaluation) 
As noted in the aouve list, there are many needs for adoitionai purchas: documents and coat:ing materials. Some VOC compliant coatings are commercially available but have not been recommended for use on military facilities because of limited performance data and lack of government purchasing documents. Other coatings are under development by industry and government. Although substitutions of these types of coatings will be necessary to comply with some VOC regulations, data on their requirements for surface preparation, application conditions, etc. are limited compared with the traditionally used materials. In addition, estimates of the service life of the new coatings for a particular application are likely to be less reliable than for the traditional coating systems.

\section{RECOMMENDATIONS}

New and current government environmental regulations are likely to have a major impact on the selection and use of coatings by facility engineers for coating maintenance of buildings and structures on their bases. To address the current and future problems, it is recommended that the following actions be taken within the Department of Defense:

- Clarify the DoD policy regarding compliance; that is, which rules should be controlling with respect to facility painting

- Develop purchasing documents for all materials listed in 2.4 for which there are commercially available materials and support work to develop 
materials and write purchasing documents for those that are not presently available

- Establish a task force with representatives from all branches of DoD so as to achieve 1) sustained awareness of new and forthcoming regulations and performance of new materials, 2) generic purchasing documents for materials that are available on the commercial market but for which there are no government purchasing documents, 3) frequent interaction of government personnel involved in coating research and development, specification development, purchase, and use, and 4) use of the best available coatings data in purchasing documents, guide specifications, manuals, and the like.

\begin{abstract}
Although the EPA has exempted certain halogenated hydrocarbons from air pollution regulations because they have not been shown to be precursors of ozone formation, it is recommended that substitution of these solvents in coatings defined by federal specifications not be supported. Substitution of these solvents may affect structural integrity, water pollution, health and safety in the workplace, waste disposal, etc.
\end{abstract}

\footnotetext{
Support research to develop test methods to predict performance of new VOC compliant coatings and to further understand the critical parameters involved in the use of these coatings (e.g., surface preparation, application, thickness, etc.).
} 
4. CONCLUSIONS

The Clean Air Act requires that all regions of the country meet the National Air Quality Standard by December 31, 1987. Since nearly every major metropolitan region is in a non-attainment area for ozone, EPA may recommend more stringent controls of VOC of paints and coatings.

The impact of using only coating materials that comply with California's SCAQMD Rule 1113 on the recommendations for maintenance of military facilities is shown in Appendix $B$. As is readily evident, recommendations have been made for cancellation or change of a major portion of the specifications used in the selection tables in AFM 85-3 (i.e., those enclosed by boxes in the tables in Appendix B).

Because of these proposed extensive changes in coating specifications, there is an urgent need to predict or determine the performance of low Voc coatings, understand critical parameters affecting their performance, develop purchasing documents, make recommendations for selection and use of these materials as contained in guide specifications and manuals, and keep abreast of current and proposed regulations.

\section{REFERENCES}

1. Henz, D.J., Air Pollution Standards and Regulations, in Handbook of Air Pollution Technology, ed. by Calvert, S. and Englund, H.M., John Wiley and Sons, New York, 1984, pp. 919-967. 
2. "Report on the Fourteenth APCA Government Affairs Seminar," Journal of the Air Pollution Control Assoc., June 1986, p. 685.

3. "Tri-Service Paints and Protective Coatings Manual," ARMY TM 5-618, NAVFAC MO-110, AIR FORCE AFM 85-3, Superintendent of Documents, U.S. Government Printing Office, washington, D.C. 20402, June 1981.

4. Connor, Raymond, "Comments on APCJ's VOC Series," Amer. Paint and Coatings Journal, August 18, 1986, p. 14.

5. Thomas, Lee M. "A Strategy for Controlling Ozone," Journal Air Pollution and Control, Sept. 1986, p. 997.

6. "Plan of Action for the Control of FSC 8010 Volatile Organic Compounds in Department of Defense Operations," Fort Belvoir Research, Development and Engineering Center, October 1986. 

Appendix A. California South Coast Air Quality Management District

Architectural Coatings Rule 1113 and Coating of Metal Parts

and Products Rule 1107

A -1 
(Adopted Sept. 2, 1977) (Amended Dec. 2, 1977) (Amended Feb. 3, 1978) (Amended Sept. 5, 1980) (Amended Apr. 3, 1981) (Amended July 3, 1981) (Amended by the Calif. ARB Oct. 21, 1981) (Amended Aug. 5, 1983) (Amended Mar. 15, 1984) (Amended Aug. 2, 1985) (Amended Nov. 1, 1585)

RULE 1113. ARCHITECTURAL COATIIGS

(a) (1) A person shall not sell, offer for sale, or apply any architectural coating manufactured after December 31, 1981 which:

(A) contains more than 250 grams of volatile organic compounds per liter of coating (2.08 pounds per gallon) excluding water and any colorant added to tint bases, except as provided in subsection (a) (2) or

(B) contains more than 380 grams of volatile organic compounds per liter of coating ( 3.17 pounds per gallon), excluding water and any colorant added to tint bases, is defined as a non-flat coating, and is manufactured prior to September 2, 1989.

(C) is recommended for use as a bituminous pavement sealer unless it is an emulsion-type coating.

(2) A person shall not sell, offer for sale or apply any architectural specialty coatina which exceeds the following limits (expressed as grams of VOC per liter of coating as applied, exciuding water) manufactured after the date listed below:

\section{Effective Effective Effective Sept. 1, 1984 Sept. 1, 1986 Sept. 1, 1987}

Varnish

Lacquer

Semi-transparent Stains

Opaque Stains

Semi-transparent and $\mathrm{Clear}$ Wood Preservatives

Opaque Wood Preservatives

General Primers, Sealers and Undercoaters

Specialty Primers, Sealers, and Undercoaters

Industrial Maintenance

Primers and Topcoats*

Alkyds

Catalyzed Epoxy

Bituminous Coatings Materials

Inorganic Polymers

Vinyl Chloride Polymers

Chlorinated Rubber

Acrylic Polymers

Urethane Polymers

Silcones

Unique Vehicles
500

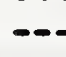

-..

-..

350
680

-..

-..

$--$

350

350

400

$-\cdot$

350

350

400

$-\infty$

350

$-\cdots$

$-\infty$

350

$500 \star \star$

420

420

420

$500=\star$

-..

420

-.-

-.-

420

420

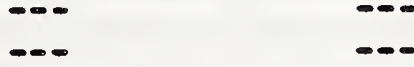

420

420

$\cdots$

420

420

$---\quad 420$

420

-.-

$--$

-.-

420 
Dry Fog Coatings

Flats

Non-Flats

Quick Dry Enamels

Specialty Flats

Waterproof Sealers

Concrete Curing Compounds

420

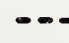

400

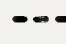

400

$\ldots+\cdots-100$

Roof Coatings

Waterproofing Mastic

Coatings

Enamel Undercoaters

Traffic Paints

-.- $\quad-.-\quad 400$

-.- $\quad-.-350$

$\cdots \quad---\quad 300$

For public streets and highways

250

450

300

350

For other surfaces

Black traffic coatings

$-\infty$

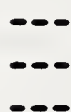

250

250

250

* A coatings category is determined by the generic polymer component present in the finished product in the largest quantity by weight.

* This limit shall become effective on September 1, 1985.

(b) The provisions of section (a) of this rule shall not apply to architectural coatings sold in this district for shipment outside of this district or for shipment to other manufacturers for repackaging.

(c) The provisions of section (a) shall not apply to:

(1) architectural coatings supplied in containers having capacities of one liter or less.

(2) architectural coatings recomended by the manufacturer for use solely as one or more of the following:

(A) fire retardant coatings.

(B) tile-like glaze coatings.

(C) mastic texture coatings.

(D) metallic pigmented coatings.

(E) swimming pool paints.

(F) multi-color paints.

(G) quick dry primers, sealers and undercoaters.

(H) shellac.

(I) sign (graphic arts) coatings.

(J) bond breakers.

(K) below ground wood preservative coatings.

(L) dry fog coatings (until September 1, 1984).

(d) In order to maintain an exemption beyond December 31, 1983, a business granted an exemption pursuant to subsection (a)(2) and (c) (2) of this rule shall, within three months after the end of each calendar year, commencing with 1983, file with the Executive Officer a report on the annual sales in gallons in California of the following coatings:

(1) Spectalty flat coatings,

(2) Quick dry enamels,

(3) Enamel undercoaters, 
(4) Quick dry primers, sealers, and undercoaters, (5) Specialty primers, sealers, and undercoaters.

(e) Containers for all coatings subject to section (a) shall display the date of manufacture of the contents or a code indicating the date of manufacture. The manufacturers of such coatings shall file with the Executive Officer of the District and the Executive Officer of the California Air Resources Board prior to September 2, 1981, an explanation of each code.

(f) If anywhere on an exempt coating coniainer, or any sticker or label affixed thereto, or in any sales or advertising literature any indication is given that such exempt coating may be used or is suitable for use for any purpose other than those specifically provided for in section (c) of this rule, then the exemption provided for in said section (c) shall not apply to that coating.

(g) In any instance where more than one of the standards set forth in section (a) of this rule may be applicable, the most restrictive standard shall apply.

(h) A person shall not use, sell or offer for sale for use in the District, in containers of 0.94 liter (one quart) capacity or larger, any architectural coating containing photochemically reactive solvent, as defined in Rule 102. The provisions of this subsection shall not apply to those coatings in compliance with subsections $(a)(1)(A),(B)$, and $(a)(2)$ of this rule.

(i) A person shall not thin or dilute any architectural coating with a photochemically reactive solvent, except that thinning of coatings in compliance with subsections $(a)(1)(A),(B)$, and $(a)(2)$ of this rule is permissible if the volatile organic compound content of such coating after thinning does not exceed the limits specified in the applicable subsections.

(j) Containers for all coatings subject to the requirements of this rule shall carry a statement of the manufacturer's recommendation regarding thinning of the coating. This recommendation shall not apply to the thinning of architectural coatings with water. The recormendation shall specify that the coating, except Industrial Maintenance, is to be employed without thinning or diluting under normal environmental and application conditions, unless any thinning recommended on the label for normal environmental and application conditions does not cause a coating to exceed its applicable standard. The recomendation on Industrial Maintenance Coatings containers shall state that the coating may be thinned or diluted in the amount needed to be compatible with the existing application and environmental conditions.

This section applies to coatings, except Industrial Maintenance, manufactured after January 1, 1985 and for Industrial Maintenance Coatings manufactured after January $1,1986$. 
(k) The VOC content of coatings subject to the provisions of this rule shall be determined by the procedure outlined in Rule 107 after the coating has been thinned as recommended on the label for normal environmental and application conditions.

(1) Definitions

For the purpose of this rule, the following definitions shall apply:

(1) Architectural Coatings

Any coatings applied to stationary structures and their appurtenances, to mobile homes, to pavements, or to curbs.

(2) Below Ground Wood Preservatives

Heavy duty coatings formulated solely for the purpose of protecting below ground wood from decay or insect attack and which contain a wood preservative chemical registered by the California Department of Food and Agriculture. These coatings perform their function by penetrating into the wood.

(3) Bituminous Coatings Materials

Black or brownish coating materials, soluble in carbon disulfide, consisting mainly of hydrocarbons and which are obtained from natural deposits, or as residues from the distillation of crude petroleum oils, or of low grades of coal.

(4) Bond Breakers

Coatings whose sole purpose, when applied between layers of concrete, is to prevent the freshly poured top layer of concrete from bonding to the substrate on which it is poured.

(5) Concrete Curing Compounds

Coatings whose sole purpose is to retard the evaporation of water from the surface of freshly cast concrete, thereby strengthening it.

(6) Dry Fog Coatings

Coatings which are formulated so that when sprayed, overspray droplets dry before falling on floors and other surfaces.

(7) Enamel Undercoaters

Coatings which are designed to be applied to a new surface over a primer or over a previous coat of paint, in order to improve the seal, provide better adhesion and make a smooth base for non-flat coatings.

(8) Fire Retardant Coatings

Coatings designed to retard fires and which will significantly:

(A) reduce rate of flame spread on the surface of a material to which such a coating has been applied, or

(B) resist ignition when exposed to high temperatures, or

(C) insulate a substrate to which such a coating has been applied and prolong the time required to reach ignition temperature.

(9) Fat Coatings

Coatings which register gloss less than 15 on an $85^{\circ}$ meter or less than five on a $60^{\circ}$ meter, or which is labeled as a flat coating.

(10) General Primers

Coatings which are intended to be applied to a surface to provide a firm bond between the substrate and subsequent coats.

(11) General Sealers 
Coatings which are intended for use on porous substrates to protect the substrate, to prevent subsequent coatings from being absorbed by the substrate, or to prevent harm to subsequent coatings by materials in the substrate.

(12) General Undercoaters

Coatings which are designed to provide a smooth surface for subsequent coats.

(13) Graphic Arts Coatings (Sign Paints)

Coatings which are marketed solely for application to indoor and outdoor signs and include lettering enamels, poster colors and bulletin coiors.

(14) Industrial Maintenance Primers and Topcoats

Coatings which are intended to be applied to a surface prior to the application of an industrial maintenance topcoat, to provide a firm bond between the substrate and subsequent coats and high performance coatings which are formulated for the purpose of heavy abrasion, water immersion, chemical, corrosion, temperature, electrical or solvent resistance.

(A) Alkyds

Synthetic resins formed by the condensation of polyhydric alcohols with polybasic acids.

(B) Catalyzed Epoxy

Crosslinking resins made by the reaction of epoxides with other materials such as amines, alcohols, phenols, carboxylic acids, and unsaturated compounds.

(C) Bituminous Coatings Materials

Black or brownish coating materials, soluble in carbon disulfide, consisting mainly of hydrocarbons and which are obtained from natural deposits, or any residues from the distillation of crude petroleum oils, or of low grades of coal.

(D) Inorganic Polymers

Substances whose principle structural features are made up on homopolar interlinkages between multivalent elements other than carbon. This does not preclude the presence of carboncontaining groups in the side branches, or as interlinkages between principle structural members. Examples of such polymers are ethyl and butyl silicates.

(E) Vinyl Chloride Polymers

Polymers made by the polymerization of vinyl chloride or copolymerization of vinyl chloride with other unsaturated compounds, the vinyl chloride being in greatest amount by weight.

(F) Chlorinated Rubber Resin formed by the reaction of rubber with chlorine.

(G) Acrylic Polymers

Polymers resulting from the polymerization of derivatives of acrylic acids, including esters of acrylic acid, methacrylic acid, acrylonitrile, and their copolymers. Also known as acrylic resins and acrylate resins.

(H) Urethane Polymers

Coating vehicles containing a polyisocyanate monomer reacted in such a manner as to yield polymers containing any ratio, 
(15) Lacquer

proportion, or combination of urethane linkages, active iso-

(I) Silicones cyanate groups, or polyisocyanate monomer.

A resin containing silicon unlike organic resins, which all contain carbon. The basic structure of silicones consist of silicon-oxygen linkages.

(J) Unique Vehicles

Generic polymer components not defined by any of the preceding; e.g., hypalon, phenoxy.

Clear or pigmented coatings formulated with nitrocellulose or synthetic resins to dry by evaporation without chemical reaction and to provide a quick drying, solid protective film.

(16) Mastic Texture Coatings

Coatings except waterproofing mastic coatings which are formulated to cover holes and minor cracks and to conceal surface irregularities.

(17) Metallic Pigmented Paints

Non-bituminous coatings which are formulated with metallic pigment.

(18) Multi-colored Coatings

Coatings which exhibit more than one color when applied and which are packaged in a single container and applied in a single coat.

(19) Non-flat Coatings

Coatings which register glass of 15 or greater on an $85^{\circ}$ meter or five or greater on a $60^{\circ}$ meter, and which are identified on the label as a gloss, semigloss, or eggshell enamel coating.

(20) Opaque Stains

All stains that are not classified as semitransparent stains.

(21) Opaque Wood Preservatives

All wood preservatives not classified as semi-transparent wood preservatives.

(22) Quick Dry Primers and Sealers

Primers, sealers, and undercoaters which are intended to be applied to a surface to provide a firm bond between the substrate and subsequent coats and which are dry to touch in one-half hour and can be recoated in two hours (ASTM 1640).

(23) Quick Dry Enamels

Non-flat coatings which comply with the following:

(i) Shall be capable of being appl ied directly from the container by brush or roller under normal conditions, normal conditions being ambient temperatures between $600 \mathrm{~F}$ and $80^{\circ} \mathrm{F}$;

(ii) When tested in accordance with ASTM D 1640 they shall: set to touch in two hours or less, dry hard in eight hours or less, and be tack free in four hours or less by the mechanical method test;

(iii) Shall have a $60^{\circ}$ dried film gloss of no less than 70.

(24) Roof Coatings

Coatings which are formulated for the sole purpose of preventing penetration of the substrate by water. These coatings include bituminous roof and waterproof mastic coatings. 
(25) Semi-Transparent Stains

Coatings which are formulated to change the color of a surface but not conceal the surface.

(26) Semi-Transperent Wood Preservatives

Wood preservative stains which are formulated for the purpose of protecting exposed wood from decay or insect attack by the addition of a wood preservative chemical registered by the California Department of food and Agriculture, and which are formulated to change the color of a surface but not conceal the surface. These coatings perform their function by penetrating into the wood.

(27) Shellacs

Clear or pigmented coatings formulated with natural resins (except nitrocellulose resins), thinned with alcohol, and formulated to dry by evaporation without a chemical reaction and are intended to provide stain blocking properties as well as a solid protective film.

(28) Specialty Flat Products

Self-priming flat products used only to perform one of the following functions: repair fire, smoke, or water damage; neutralize odors; block stains; or coat acoustical materials without affecting their acoustical properties.

(29) Soecialty Primers. Sealers, and Undercoaters

Primers, sealers and undercoaters used only to perform one of the following functions: repair fire, smoke or water damage; neutral1ze odor; block stains; block efflorescence; condition chalky surfaces; or coat acoustical materials without affecting their acoustical properties.

(30) Swimming Pool Coatings

Coatings specifically formulated to coat the interior of swimming pools and to resist swimming pool chemicals.

(31) Tile-like Glaze Coatings

Coatings which are formulated to provide a tough, extra durable coating system, which are applied as a continuous (seamless) highbutld film and which cure to a hard glaze finish.

(32) Varnishes

Clear or pigmented coatings formulated with various resins to dry by chemical reaction on exposure to air. These coatings are intended to provide a durable transparent or translucent solid protective film.

(33) Volatile Organic Compounds (VOC)

Compounds of carbon, excluding carbon monoxide, carbon dioxide, carbonic acid, metallic carbides or carbonates, ammonium carbonate, methane, 1,1,1-trichloroethane, methylene chloride, and trichlorotrifluoroethane, which may be emitted to the atmosphere during the application of and/or subsequent drying or curing of coatings subject to this rule.

(34) Waterproofing Mastic Coatings

Weatherproof and waterproof coatings which are formulated to cover holes, minor cracks, and conceal surface irregularities and which are applied in thicknesses of at least $15 \mathrm{mils}$. 
(35) Waterproofing Sealers

Coatings which are formulated for the sole purpose of preventing penetration of porous substrates by water. 
(Adopted June 1, 1979) (Amended December 4, 1981) (Amended May 7, 1982) (Amended December 2, 1983)

(Amended March 2, 1984)

RULE 1107. COATHHG OF HETAL PARTS AMD PRODUCTS

(a) Definitions

For the purpose of this rule, the following definitions shall apply:

(1) Metal Parts and Products are any components or complete units fabricated from metal, except those subject to the coating provisions of other source specific rules of Regulation XI.

(2) Volatile Organic Compound (VOC) is any volitile compound of carbon, excluding methane, carbon monoxide, carbon dioxide, carbonic acid, metallic carbides or carbonates, ammonium carbonate, 1,1,1trichloroethane, methylene chloride, trifluoroethane and chiorinated-fluorinated hydrocarbons.

(3) Transfer Efficiency is the ratio of the weight or volume of coating solids adhering to an object to the total weight or volume, respectively, of coating solids used in the application process expressed as a percentage.

(4) Touch-Up is that portion of the coating operation which is incidental to the main coating process but necessary to cover minor imperfections.

(5) Repair is recoating portions of a previously coated product due to mechanical damage to the coating following normal painting operations.

(6) Metallic Coating is a coating which contains more than 10 grams per liter ( 0.08 pound per gallon) of metal particles, as applied.

(7) Extreme Performance Coating is a coating designed for harsh exposure or exposure to any of: the weather all of the time, temperature consistently above $95^{\circ} \mathrm{C}$, detergents, abrasive and scouring agents, solvents, corrosive atmospheres or similar environmental conditions.

(8) Primary Architectural Coating is a coating used to protect architectural subsections after manufacture, until their assembly and coating as part of an architectural project.

(9) High Performance Architectural Coating is used to protect architectural subsections and meets the requirements of Architectural Aluminum Manufacturer's Association publication number AAMA 605.21980.

(10) Camouflage Coating is a coating used, usually by the military, to conceal equipment from detection.

(11) Military Specification Coating is a coating applied to metal parts and products which has a paint formulation approved by a United States Military Agency for use on Military equipment.

(12) Stencil coating is a coating applied to a template in order to add designs, letters and/or numbers to metal parts and products.

(13) Pretreatment coating is a coating, which contains a small quantity of acid to provide surface etching, applied directly to metal surfaces to provide corrosion resistance, adhesion and ease. of 
stripping.

(14) Contract painter is a non-manufacturer of metal parts and products that applies coatings to such products at his facility exclusively under contract with one or more parties which operate under separate ownership and control.

(15) Safety Indicating Coating is a coating which changes physical characteristics, such as color, to indicate unsafe conditions.

(b) Requirements

(1) Transfer Efficiency

On and after January 1, 1983, a person shall not apply coatings to metal parts and products subject to the provisions of this rule except by electrostatic attraction, flow coat or dip coat, or by other coating application method deemed by the Executive Officer to be capable of achieving a 65 percent transfer efficiency.

(2) High Performance Architectural Coatings

A person shall not apply to metal parts and products any high performance architectural coatings which contain volatile organic compounds in excess of 750 grams per liter of coatings, as applied, excluding water.

(3) Camouflage Coatings

On and after January 1, 1984, a person shall not apply to metal parts and products used by the military camouflage coatings which contain volatile organic compounds in excess of 420 grams per liter of coating, as applied, excluding water.

(4) Military Specification Coating

(A) On or after January 1,1984 , a person shall not apply to metal parts and products which will be used by the military, military specification coatings which contain volatile organic compounds in excess of the limits specified below:

(i) 420 grams per liter of coating, as applied, excluding water, when dried at temperatures below $90^{\circ} \mathrm{C}$ ( $\left.194^{\circ} \mathrm{F}\right)$;

(ii) 420 grams per liter of coating, as applied, excluding water, for extreme performance coating;

(iii) 360 grams per liter of coating, as applied, excluding water, when dried at temperatures at or above $90^{\circ} \mathrm{C}$ (1940 F).

(5) General Coatings

On and after January 1, 1983, a person shall not apply to metal parts and products except those covered by subparagraphs (b)(2), (b) (3), and (b)(4) of this rule, any coating which contains volatile organic compounds in excess of the limits specified below:

(A) 420 grams per liter of coating, as applied, excluding water, when dried at temperatures below $90^{\circ} \mathrm{C}\left(194^{\circ} \mathrm{F}\right)$;

(B) 420 grams per liter of coating, as applied, excluding water, for extreme performance coatings;

(C) 360 grams per liter of coating, as applied, excluding water, when dried at temperatures at or above $90^{\circ} \mathrm{C}\left(194^{\circ} \mathrm{F}\right)$.

(6) Demonstration Program

(A) A person applying more than 5000 gallons of general coatings and/or military specification coatings during the calendar 
year 1983 shall submit to the Executive Officer a Coatings Demonstration Plan to be used in establishing an 18-month program to demonstrate the feasibility of applying such coatings which meet the VOC limitations in subparagraph $(b)(6)(E)$.

(B) Such plan shall include strategies to demonstrate the feasibility of the limits in subparagraph $(b)(6)(E)$.

(c) Demonstration plan results shall be reported to the Executive Officer at the end of each three-month period of operation.

(D) Tests run pursuant to an approved demonstration program, and with prior notification to the Executive officer, shall not constitute a violation of any permit to operate.

(E) Intended Final Limits.

(i) 3e grams VOC per lifter of coating, as applied, excluding water, when the coated products are dried at a temDerature of $90^{\circ} \mathrm{C}$ (1940F) or below;

(ii) 275 grams VOC per liter of coating, as applied, exciuding water, when the coated products are dried at a temperature at or above $90^{\circ} \mathrm{C}(1940 \mathrm{~F})$.

(c) Equivalency

In lieu of complying with the specific limits of paragraph (b), a person may achieve compliance by means of an equivalency under this paragraph. To achieve equivalency, the emissions from the coating operation must be reduced, such that:

(1) The emission reductions are at least equal to those which would be obtained by the use of coatings and operational techniques specified in paragraph (b), and

(2) The emission reduction methods are applied to the coating operations subject to the provisions of this rule and such emission reduction methods are approved by the Executive Officer, and

(3) The owner or operator submits applications for new permits to construct or operate both basic and control equipment involved in such reductions, and

(4) Such emission reductions will occur by the applicable date specified in paragraph (b) for such compliance.

(d) Methods of Analys is

The volatile organic content of coatings subject to the provisions of this rule shall be determined by the procedure outlined in Rule 107.

(e) Exemptions

$=:$ (1) The provisions of this rule, except for paragraph (f), shall not apply to:

(A) Touch-up and repair

(B) Metallic coatings

(C) Stencil coatings

(D) Until January 1. 1985, a facility which emits a total of less than 22.7 kilograms ( 50 pounds) of volatile organic compound from coatings subject to this rule in any one day or emits less than 226.8 kilograms (500 pounds) of volatile organic 
compounds from coatings subject to this rule in any 30 consecutive days.

(E) On and after January 1, 1985, a facility which uses a total of less than three gallons of coatings subject to this rule in any one day.

(F) Primary Architectural Coatings.

(G) Coatings used in volumes less than 50 gallons in any one year, if complying coatings are not available, after petition to the Executive Officer in writing and written approval is granted by the Executive Officer.

(H) Pretreatment coatings.

(I) Safety indicating coatings.

(2) The provisions of subparagraph $(b)(1)$ of this rule shall not apply to any coating operation that, because of physical and/or chemical characteristics of substrate or safety conditions, cannot meet a 65 percent transfer efficiency, provided that:

(A) General coaters submit a written petition to the Executive Officer, setting forth the basis, including test data for the claim that 65 percent transfer efficiency cannot be met, and approval is granted by the Executive Officer.

(B) Contract painters submit a written petition to, and receive approval from, the Executive Officer to exempt the coating of such items; and:

(i) maintain a daily log which describes the reason(s) why 65 percent transfer efficiency cannot be achieved, contains a written and/or photographic description of the object to be used; and

(ii) the entry into the $\log$ is made prior to commencement of coating operations for that object; and

(iii) the daily $\log$ is made available for inspection anytime during working hours.

(3) The Executive Officer may revoke his approval in subparagraph (e) (2) (B) if:

(A) the $\log$ is not adequately maintained, or

(B) an entry is made after the application of coating, or

(C) the physical characteristics of the substrate do not warrant an exemption.

(4) The provisions of subparagraph (b)(1) shall not apply to contract painters while applying coatings to objects on trays.

(5) The provisions of this rule shall not apply to coating of marine vessels and their structural appurtenances.

(6) The provisions of this rule shall not apply to coating motor vehicle bodies at motor vehicle rework facilities.

(7) The provisions of (b)(1) shall not apply to contract painters that use less than 50 gallons of coating per day, until July 1,1984 .

(8) The provisions of subparagraph $(b)(6)$ of this rule shall not apply to any person:

(A) who complies with subparagraph (b)(1) while using coatings that meet the formulation requirements of subparagraph (b) (6) (E), or

(B) achieves emission reductions equivalent to those achieved in 
Complying with (A) above; and
(C) submits to the Executive officer, and receives approval of, a
petition which describes the basis for exemption from subpara-
graph (b) $(6)$.

(f) Rule 442 Applicability

Any coating, coating operation, or facility which is subject to this rule, shall comply with the provisions of Rule 442 until such time as compliance with the limits specified in this rule is achieved. Any coating, coating operation, or facility which is exempt from all or a portion of this rule, shall comply with the provisions of Rule 442.

(g) Compliance Schedules

(1) Any person who has not by January 1, 1982, either achieved compliance with the requirements of subparagraph (b)(5) of this rule, or achieved equivalency pursuant to paragraph (c), shall comply with the following:

(A) No later than January 1, 1982, submit a report to the District describing the techniques which will be used for achieving compliance with the requirements of said subparagraph; and

(8) No later than July 1, 1982, submit to the District copies of equipment purchases and/or construction contracts to enable compliance with the requirements of said subparagraph; and

(C) No later than September 1, 1982, submit to the District a certification that the necessary equipment has been installed and/or construction has been completed to enable compliance with the requirements of said subparagraph; and

(D) No later than January 1, 1983, submit to the District evidence demonstrating final compliance with the requirements of said subparagraph.

(2) Any person who has not by January 1, 1983, either achieved compliance with the requirements of subparagraphs $(b)(3)$ and $(b)(4)(A)$ of this rule, or achieved equivalency pursuant to paragraph (c) shall comply with the following:

(A) No later than January 1, 1983, submit a report to the District describing the techniques which will be used for achieving compliance with the requirements of said subparagraphs; and

(B) No later than July 1, 1983, submit to the District copies of equipment purchases and/or construction contracts to enable compliance with the requirements of such subparagraph; and

(c) No later than September 1, 1983, submit to the District a certification that the necessary equipment has been installed and/or construction has been completed to enable compliance with the requirements of said subparagraph; and

(D) No later than January 1, 1984, submit to the District evidence demonstrating final compliance with the requirements of said subparagraph.

(3) Any person who is subject to the provisions of paragraph (b)(6) of this rule shall comply with the following:

(A) No later than June 1, 1984, submit a Coatings Demonstration Plan for approval by the Executive Officer. 
Appendix B. Summary of AFM 85-3 Coating Recommendations Affected by

SCAQMD Rule 1113 


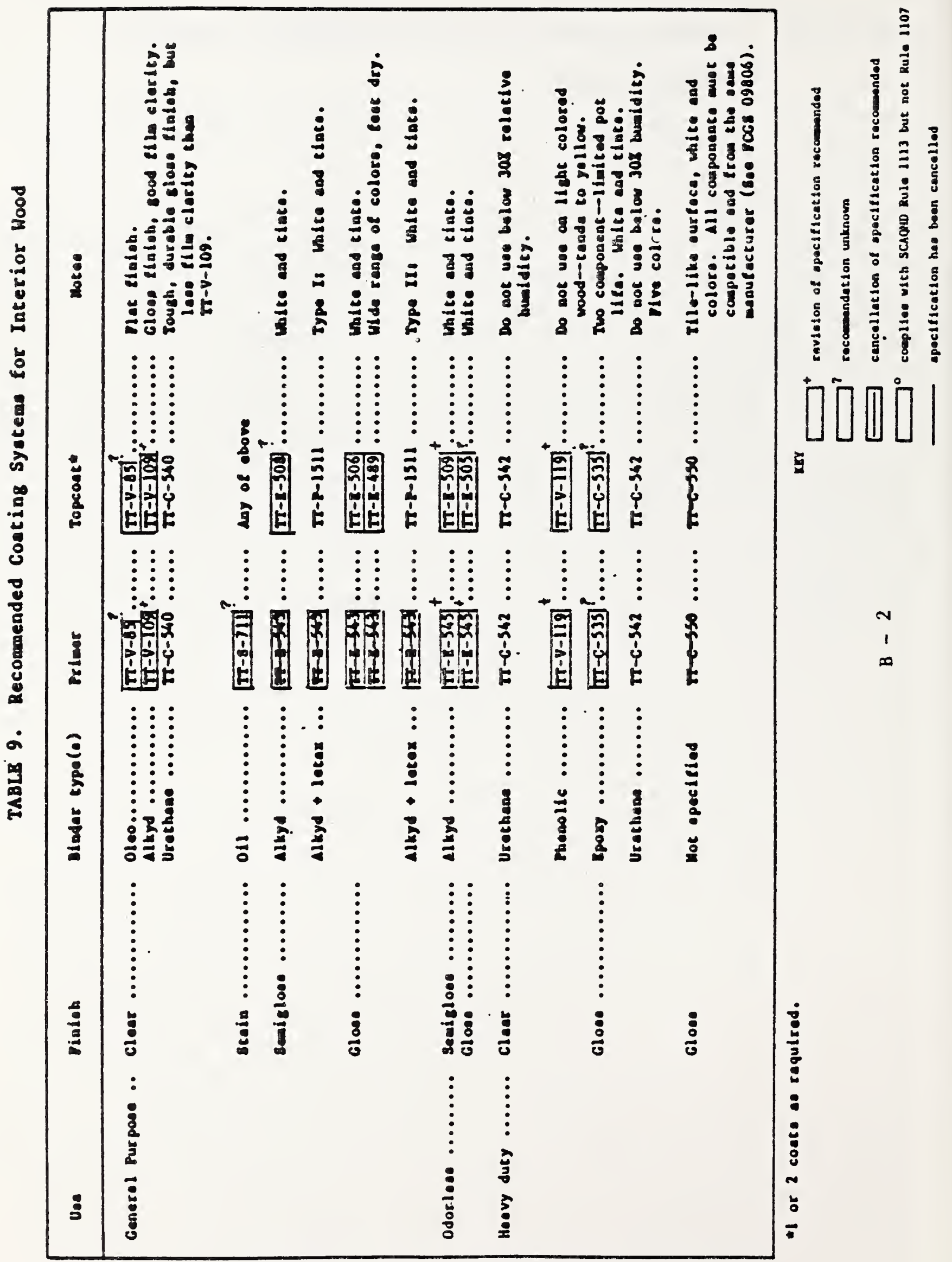




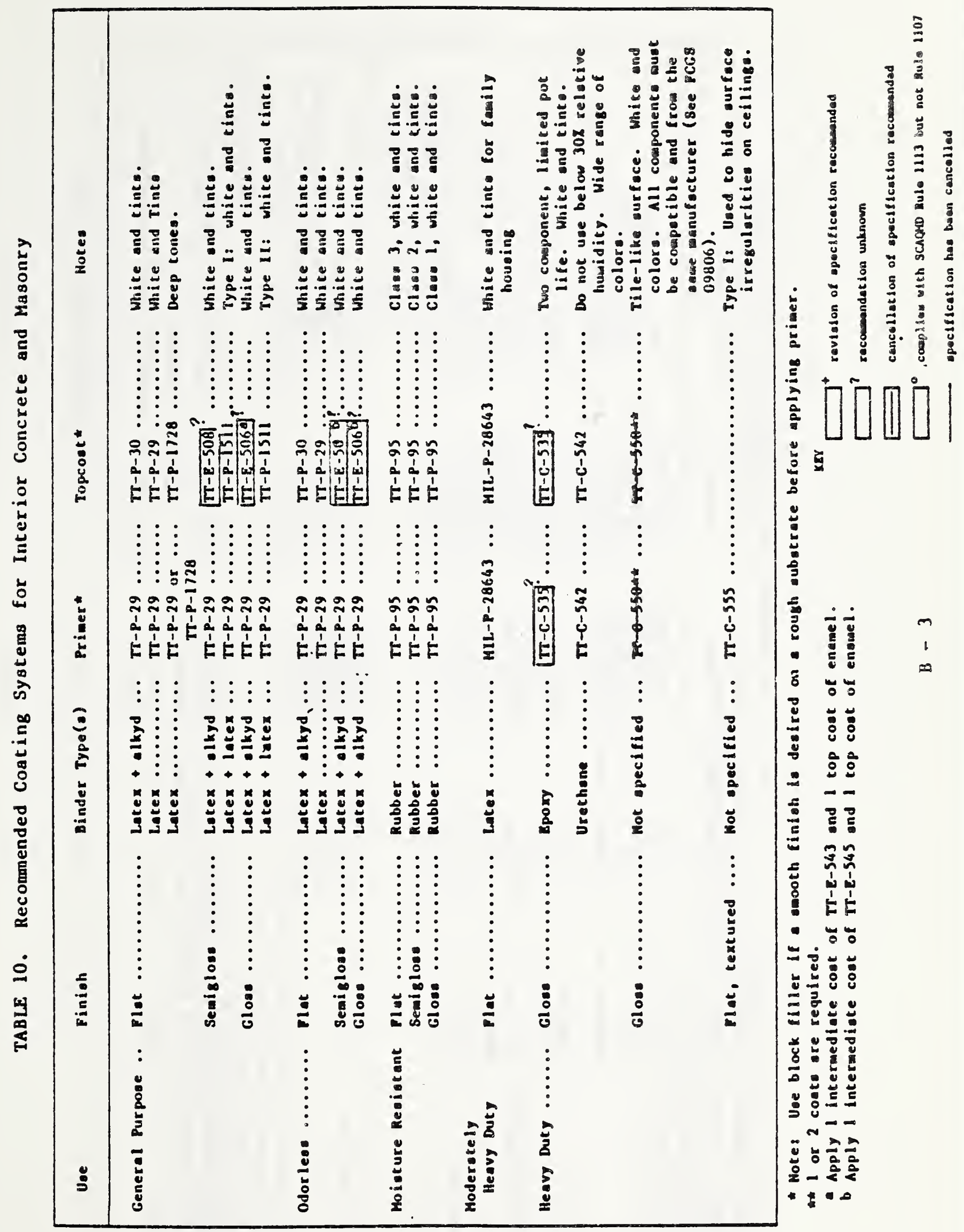




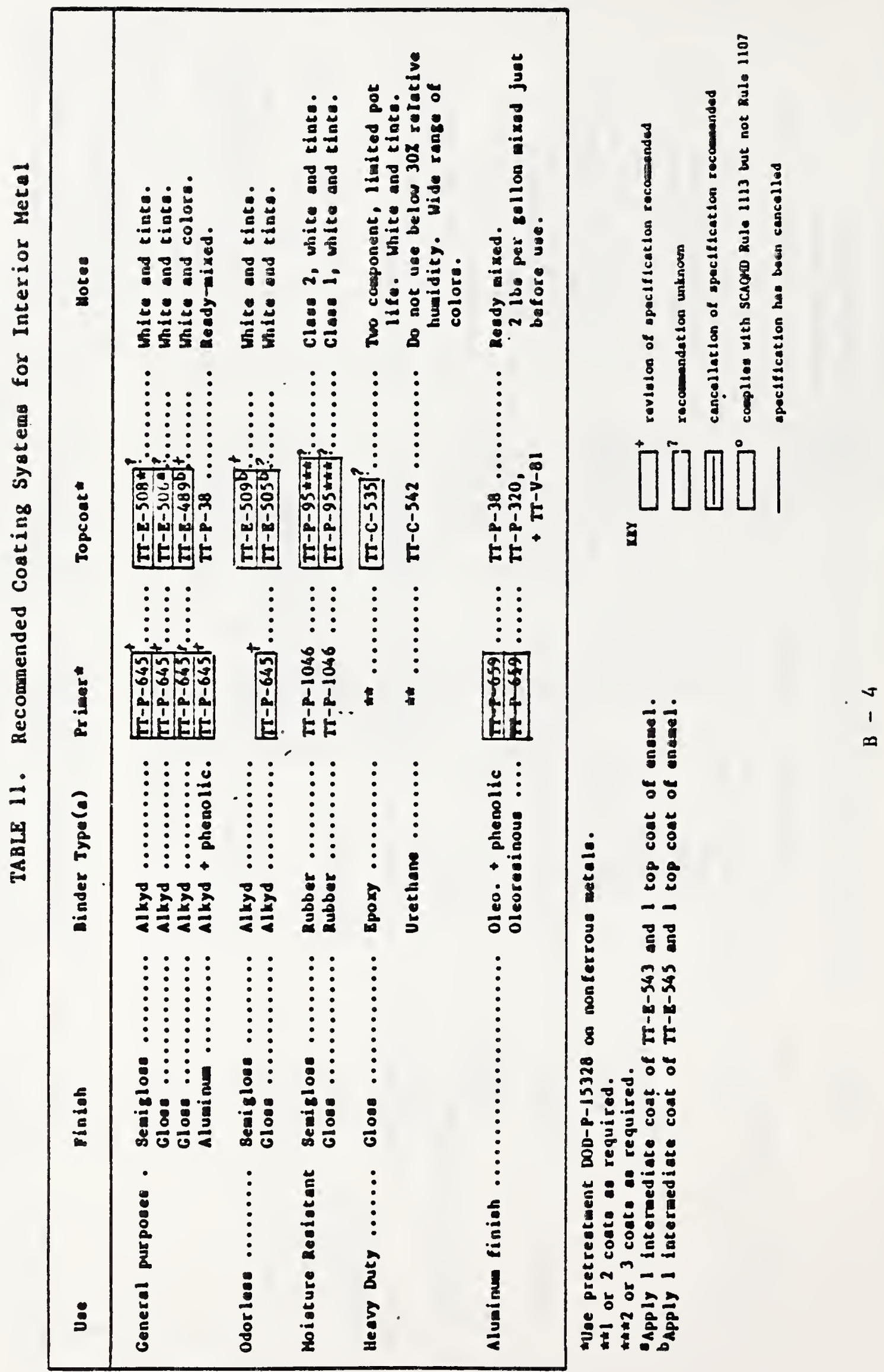




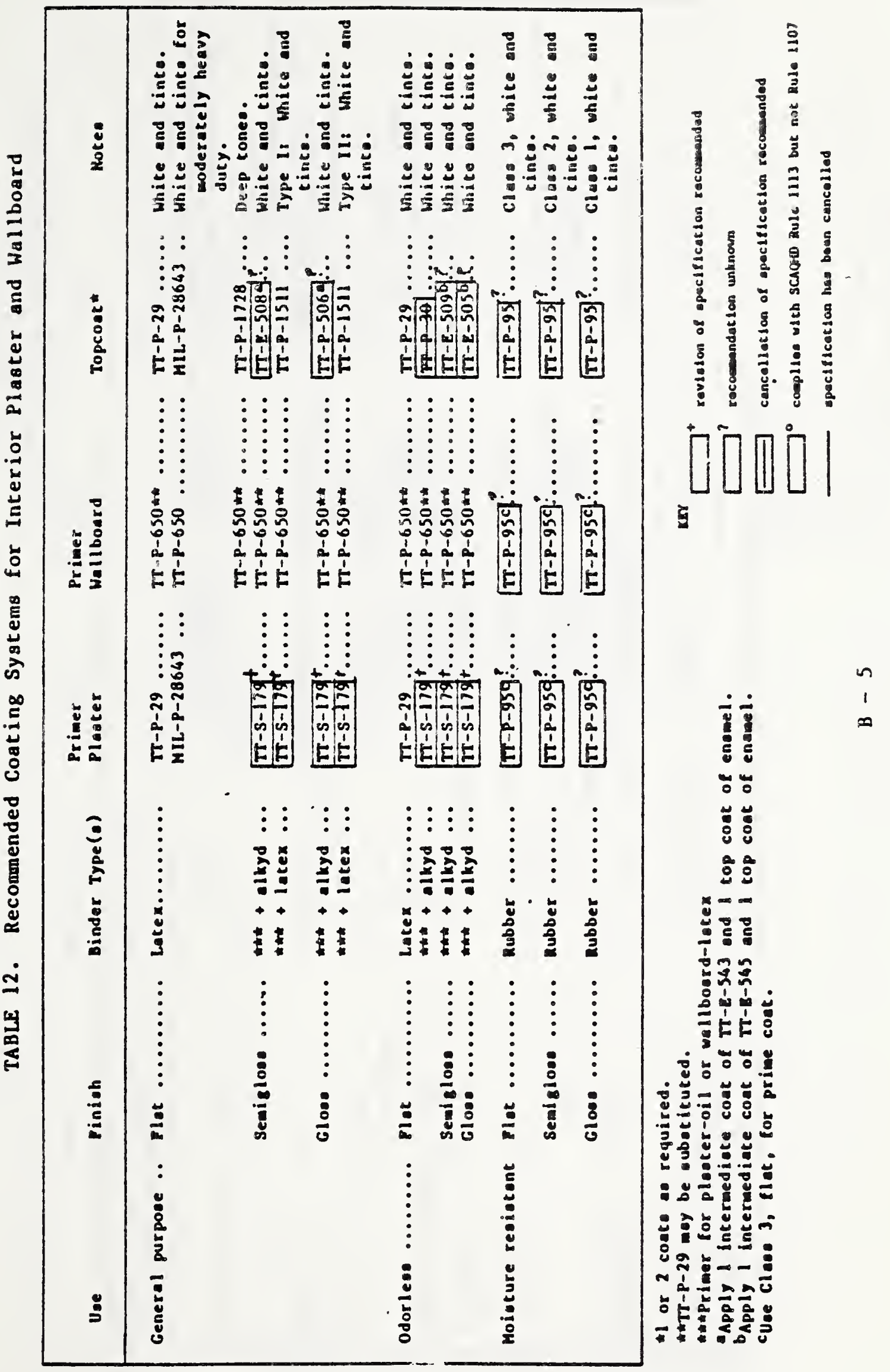




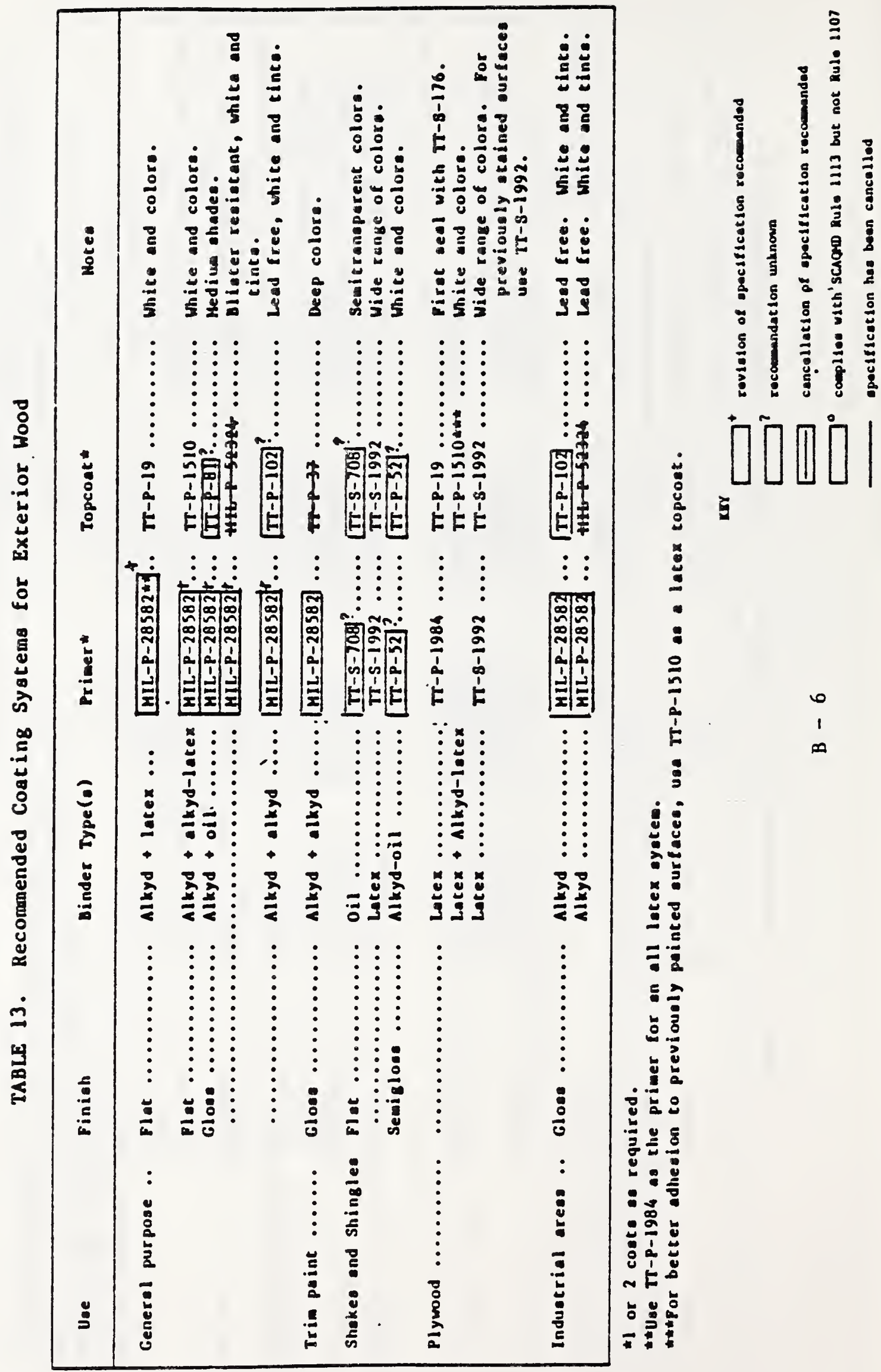




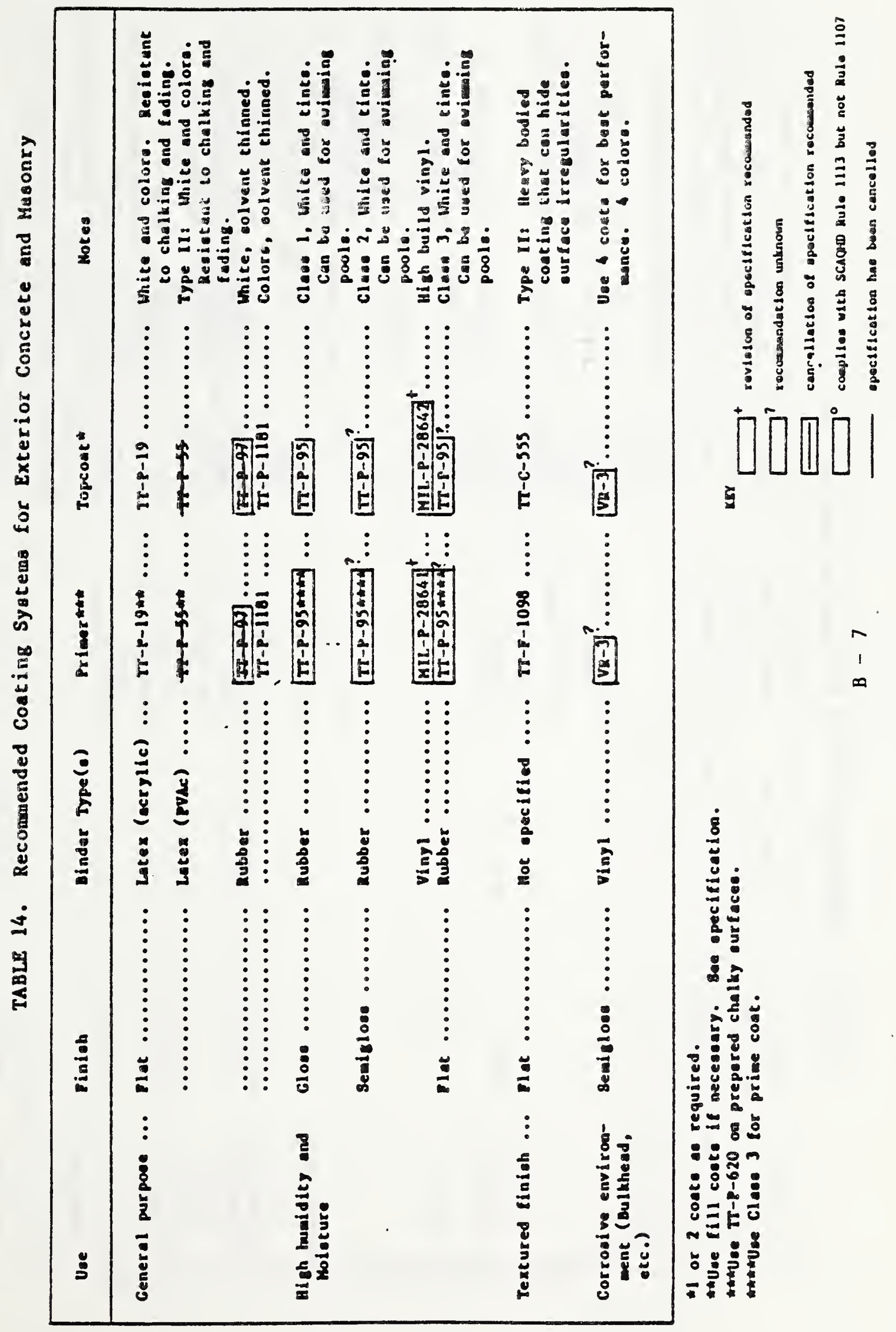




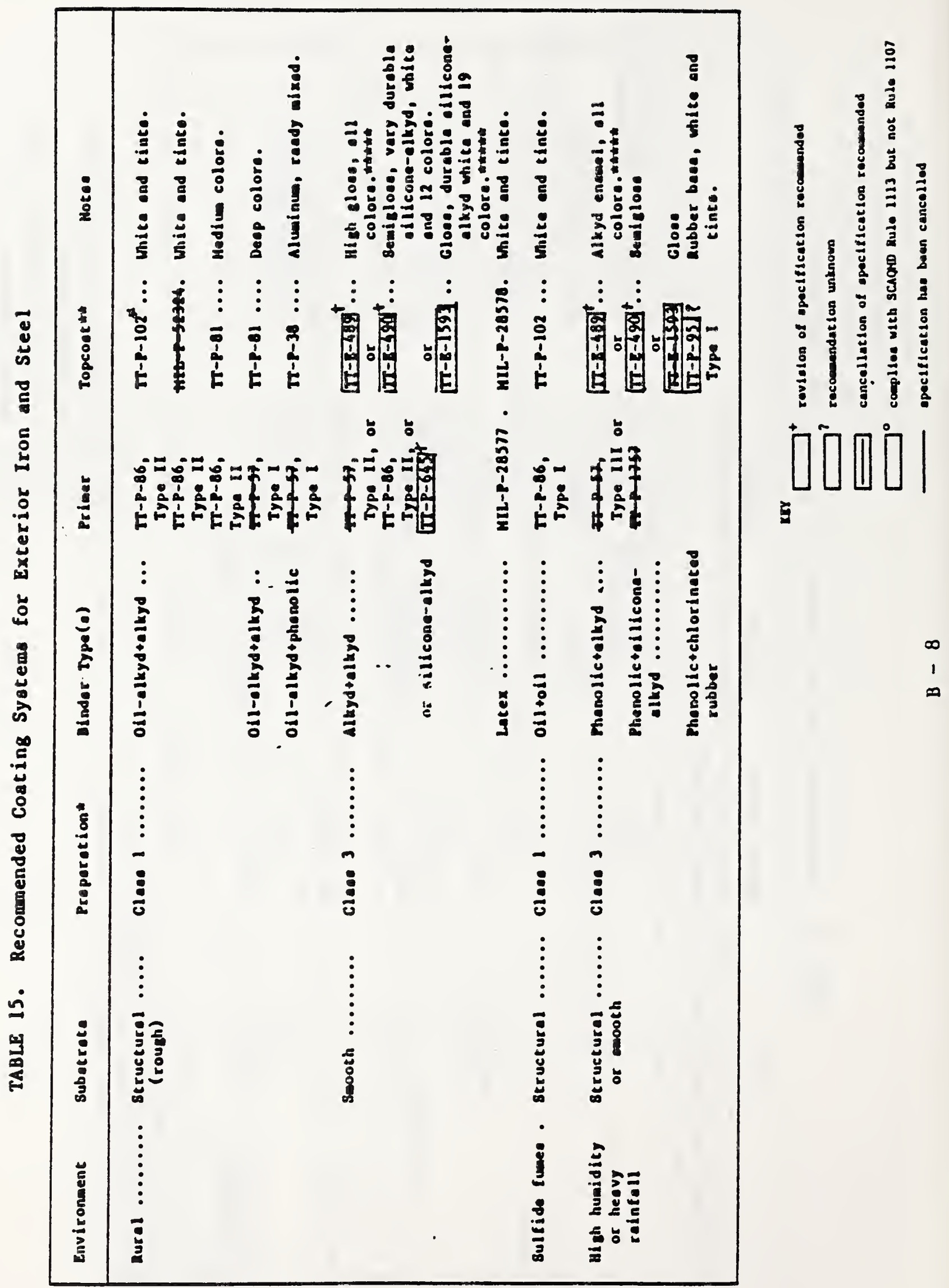




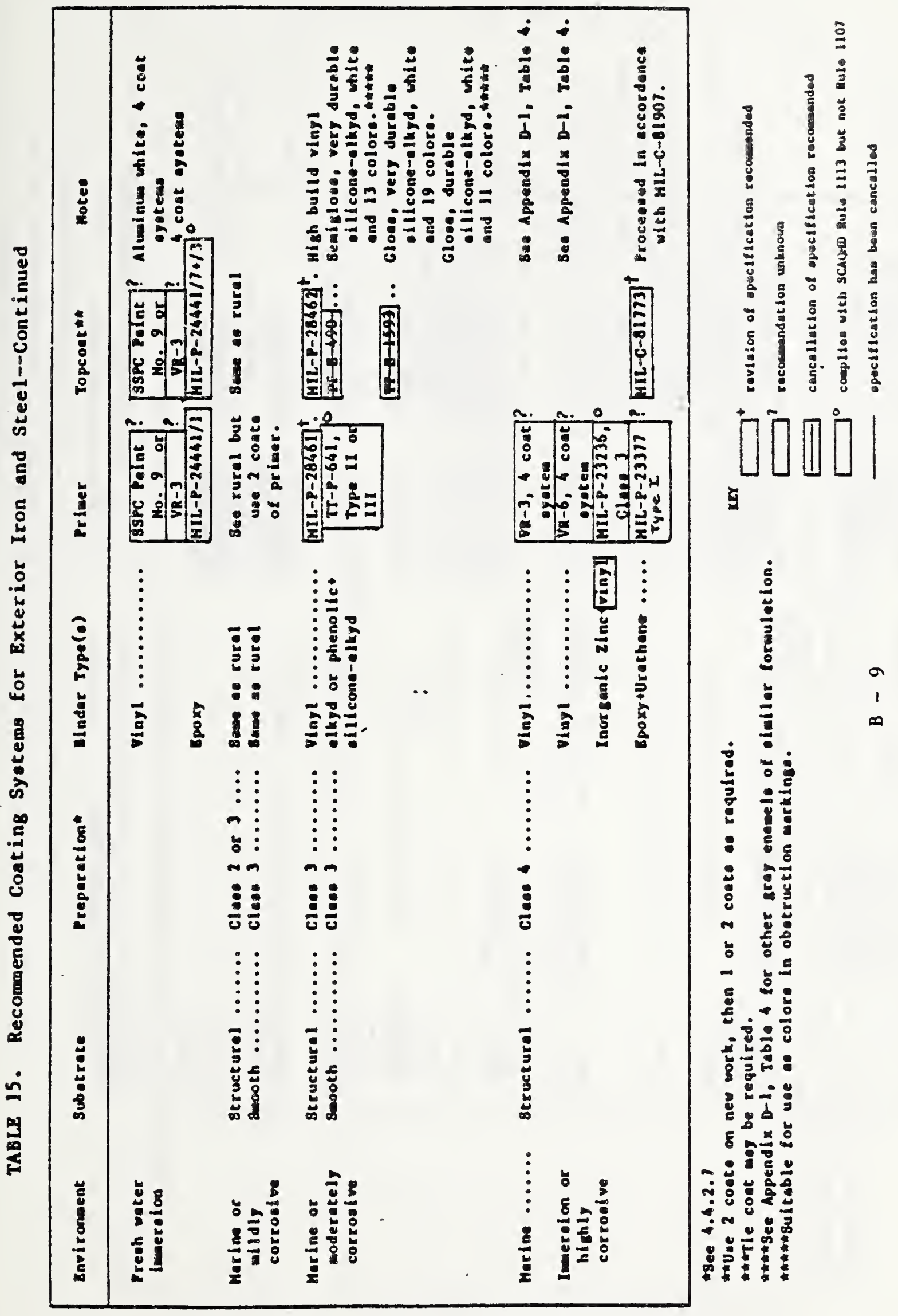



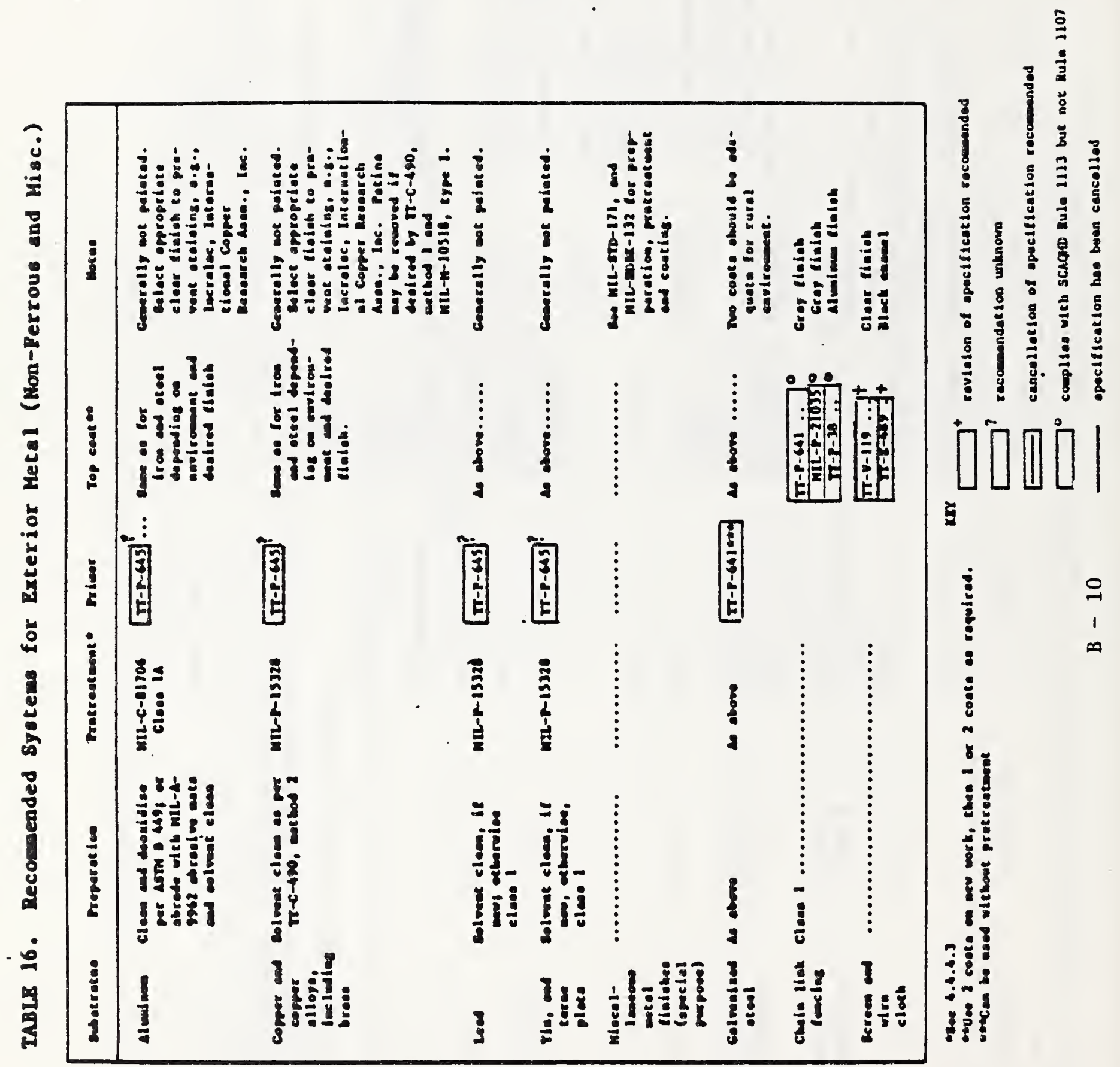


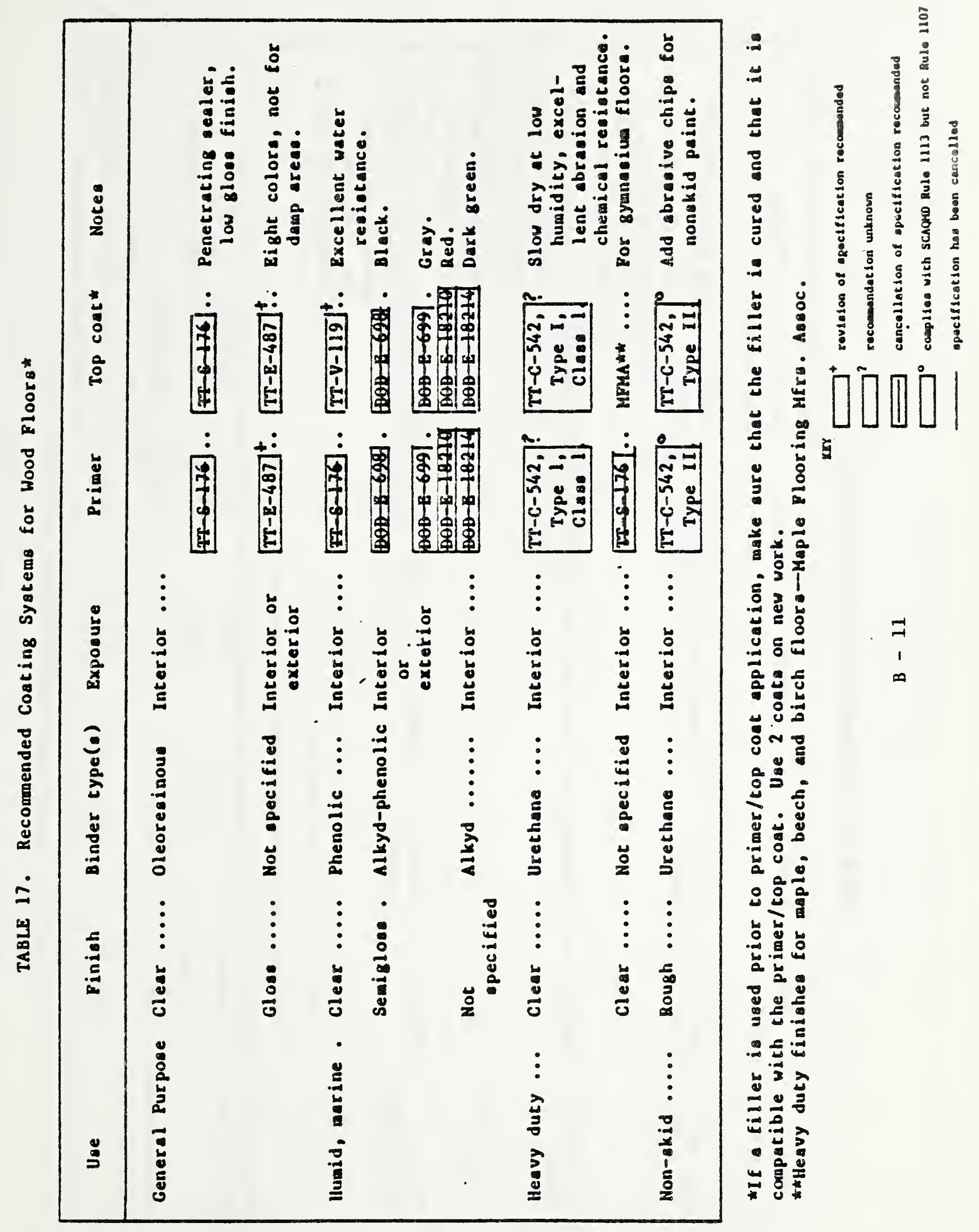



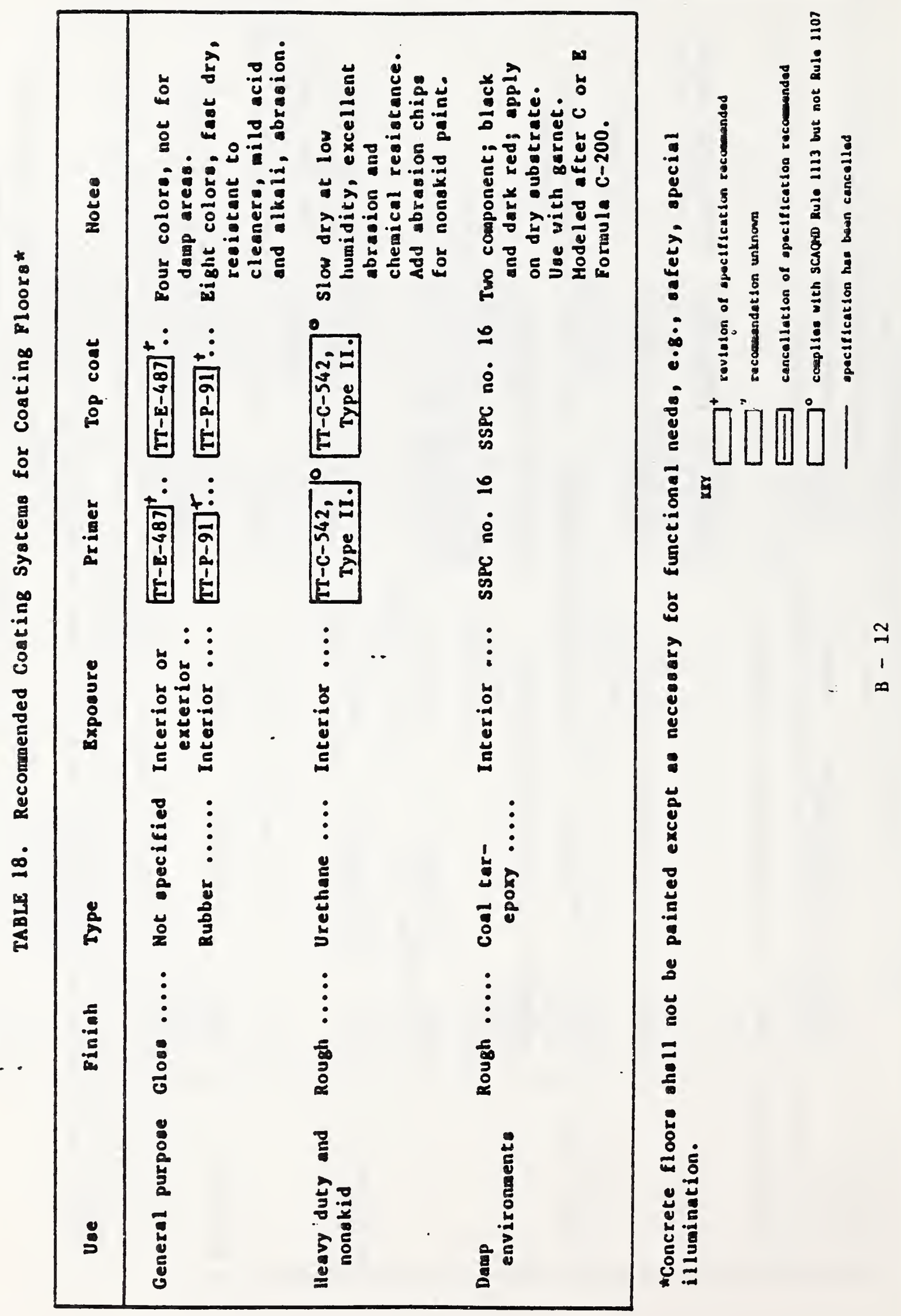


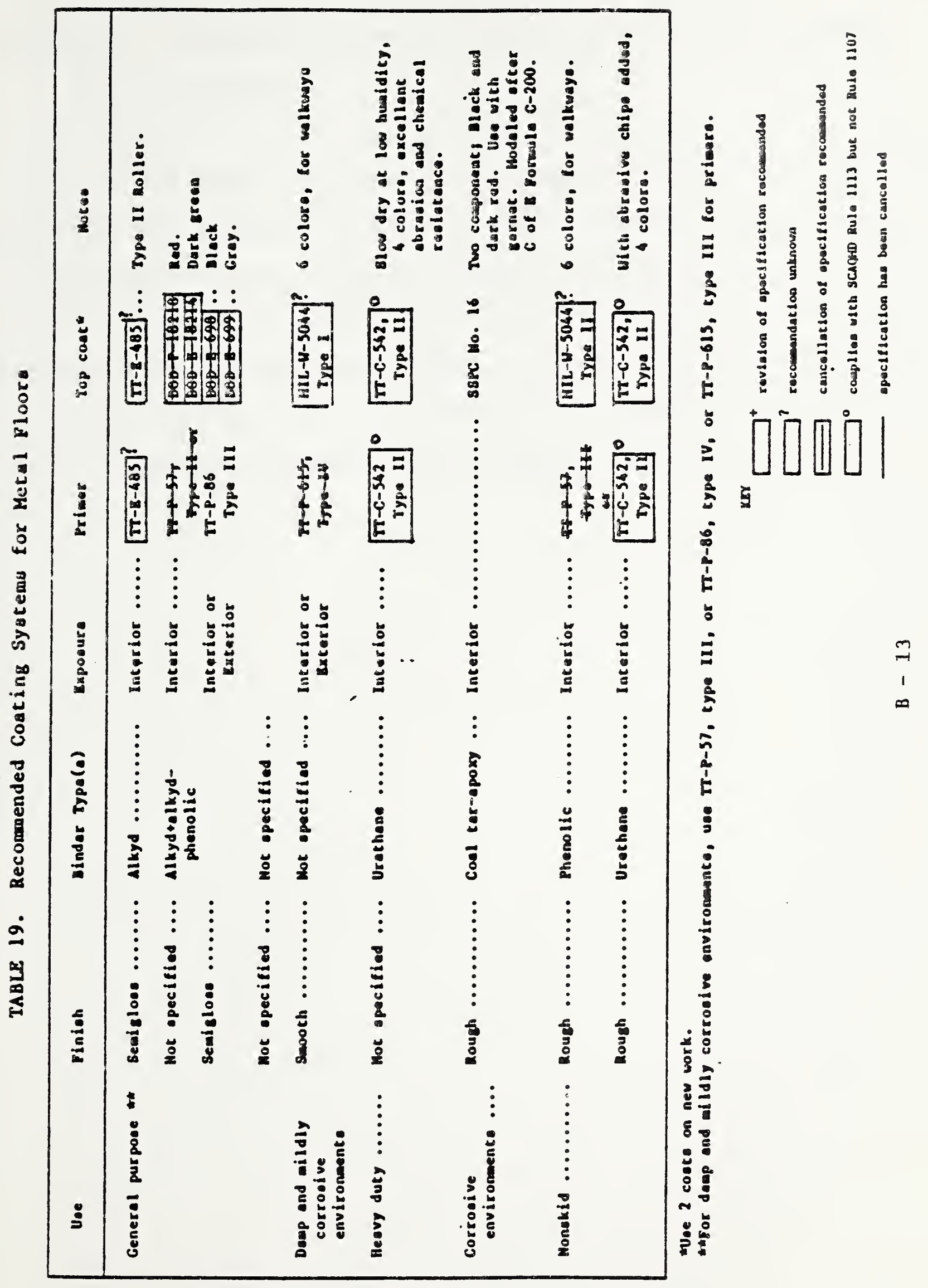


Appendix C. Suggested Replacements for Non-Compliant Coatings Recommended in $A F M$ 85-3

The criterion used for replacement of non-compliant coatings with compliant ones was that the coatings meet SCAQMD Architectural Coatings Rule 1113. Some of the replacement coatings do not meet SCAQMD's Coating of Metal Parts and Products Rule 1107. These coatings include MIL-P-24441 and TT-C-542, which are recommended in many of the selection tables. In addition there are no exemptions for specialized coatings in Rule 1107. Thus, TT-P-95 would not be compliant for use in swimming pools and most metallic pigmented coatings would not comply. 



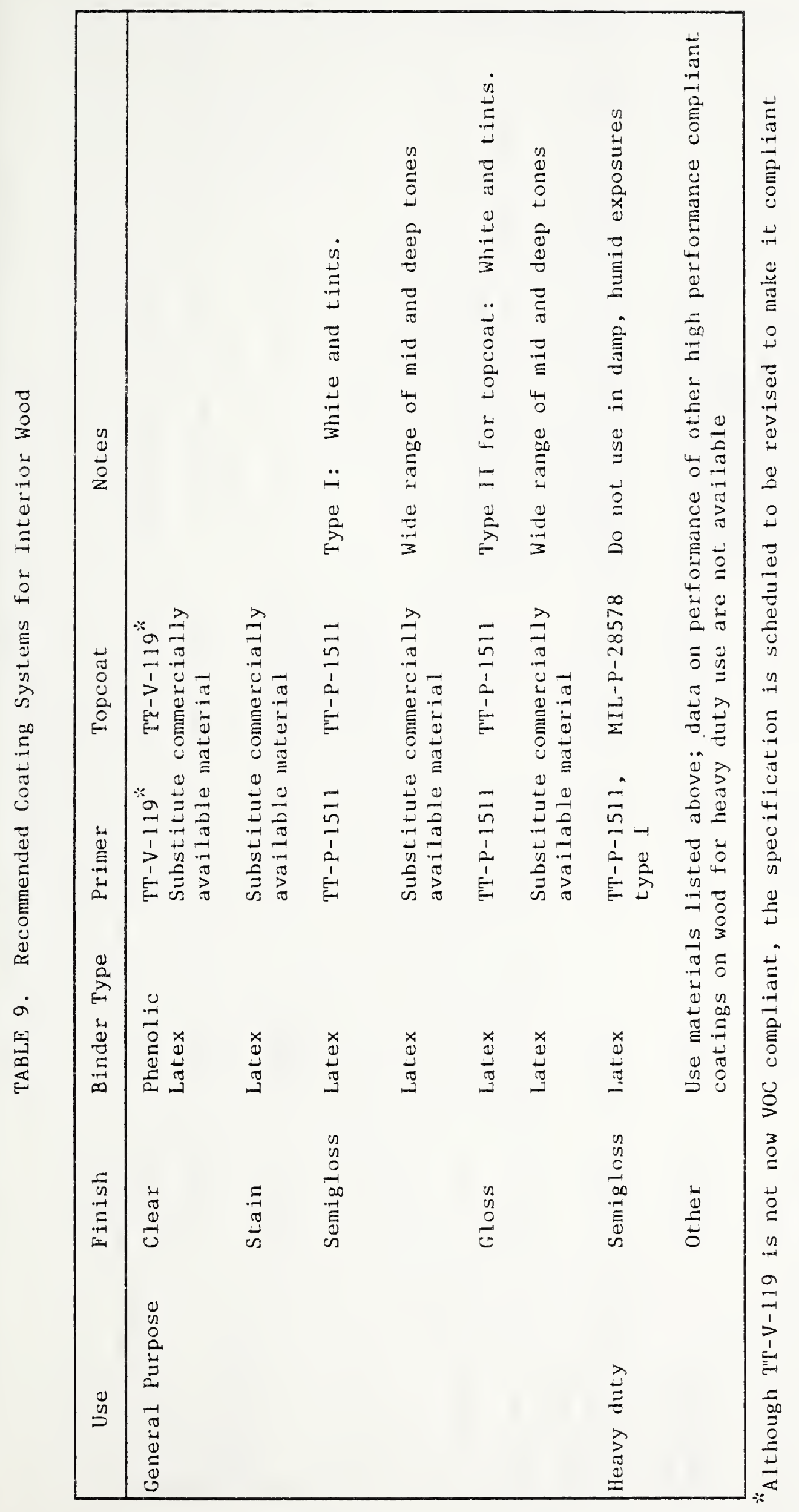




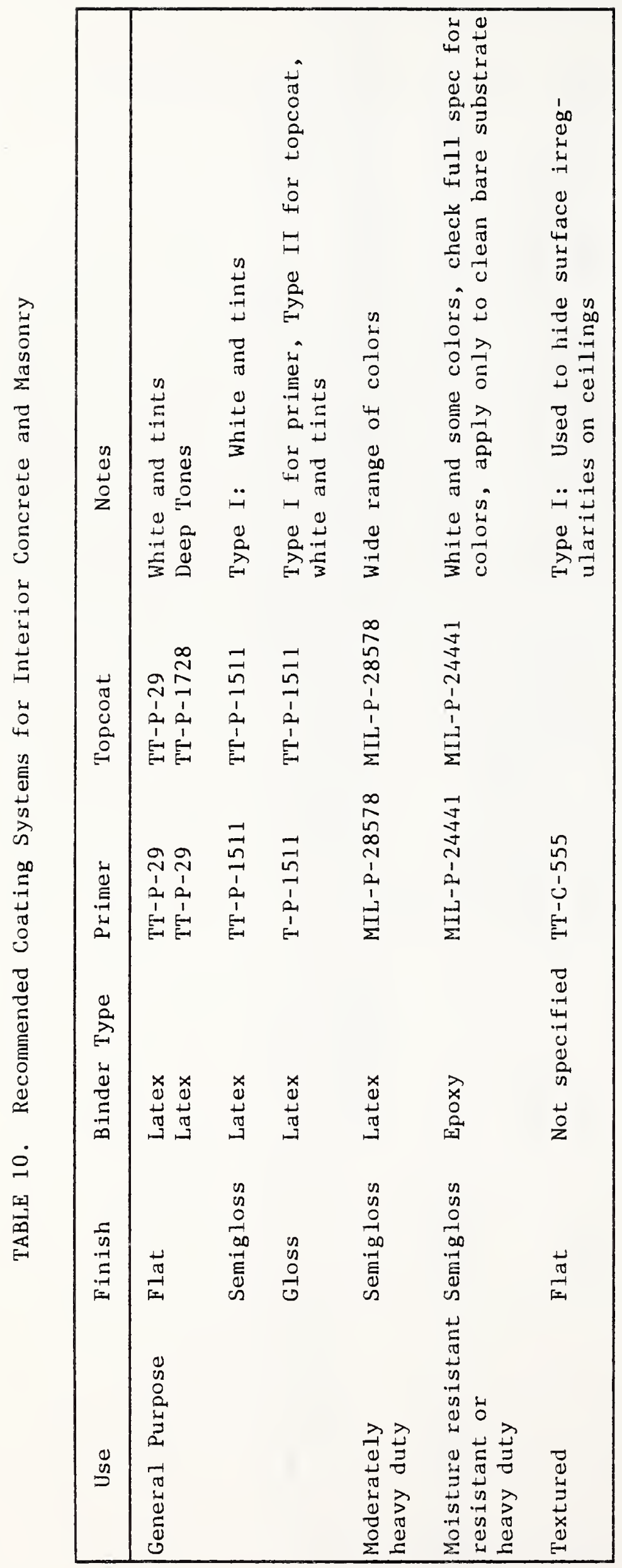




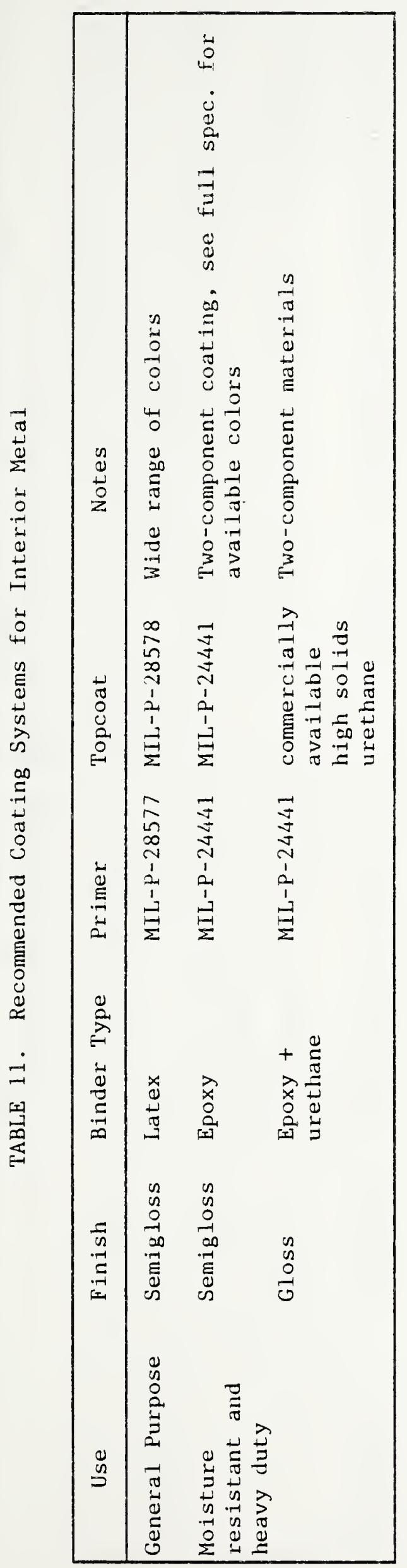




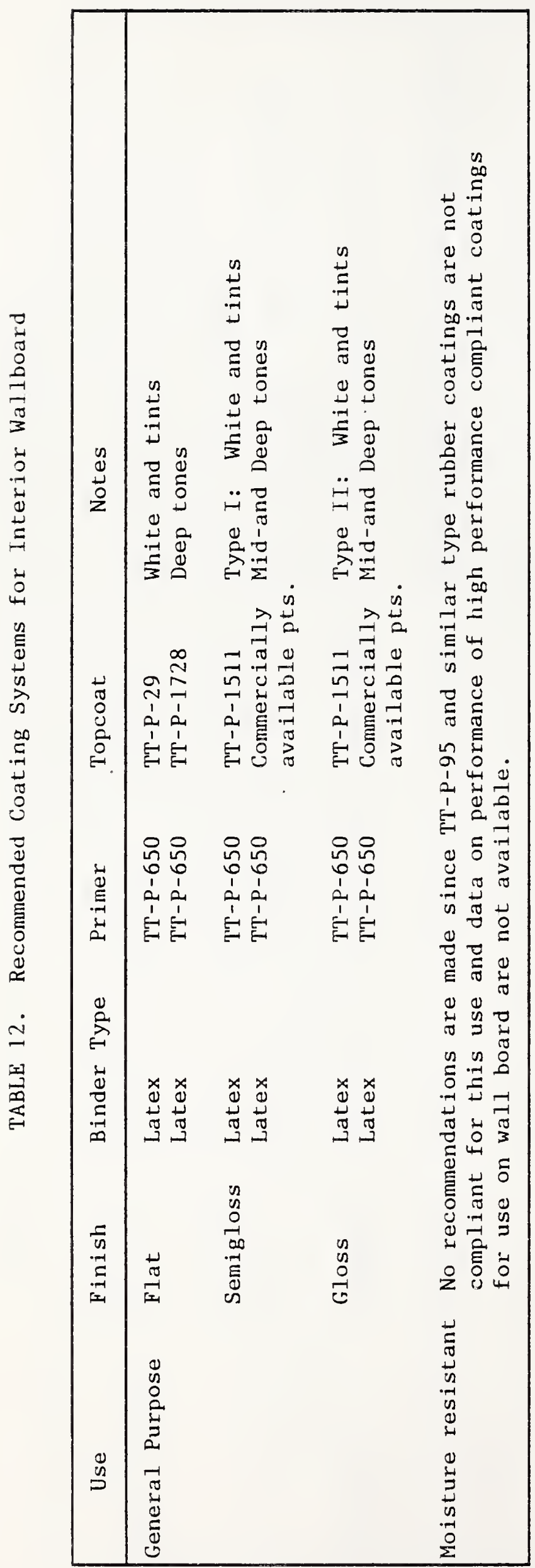




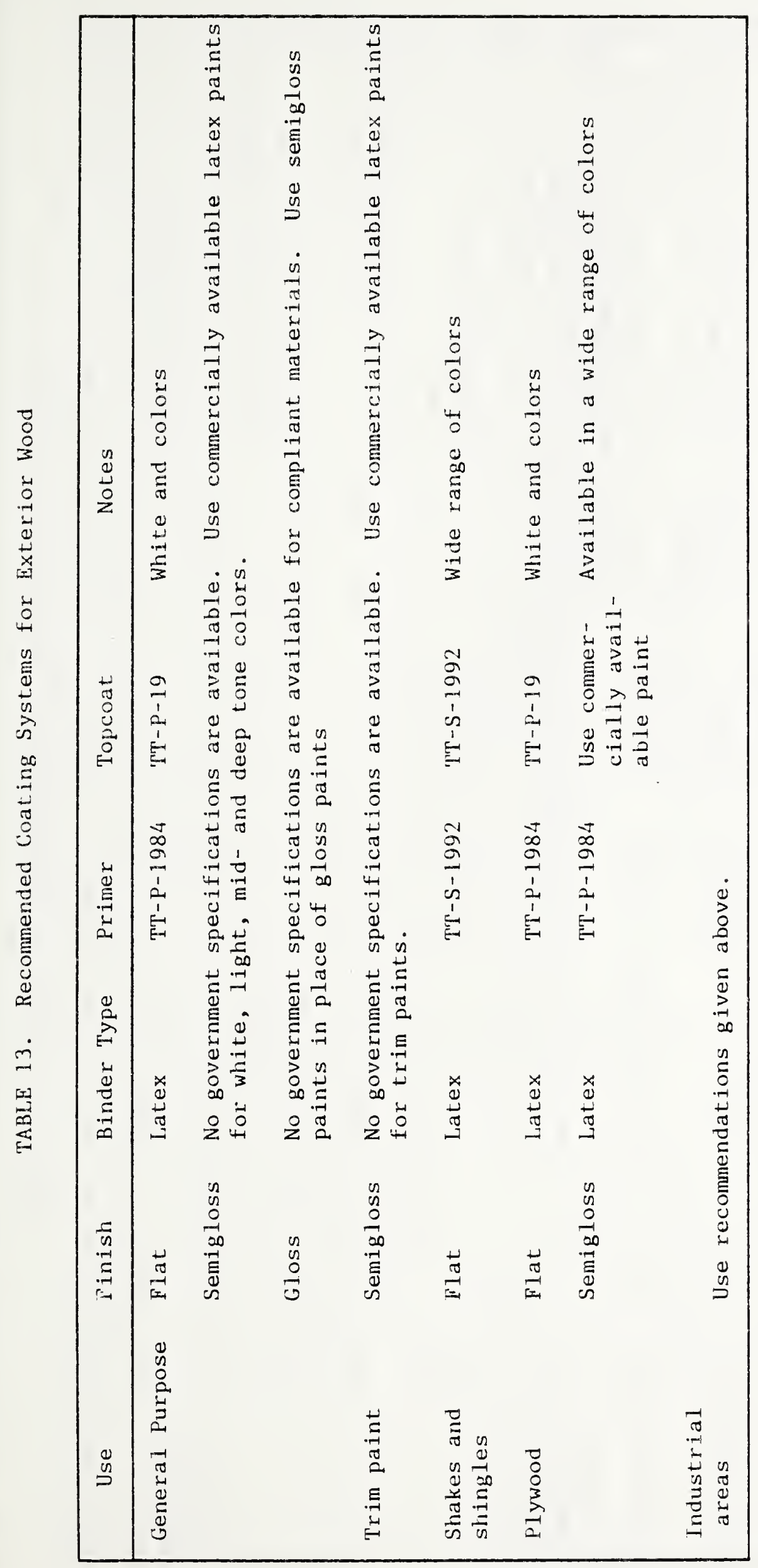




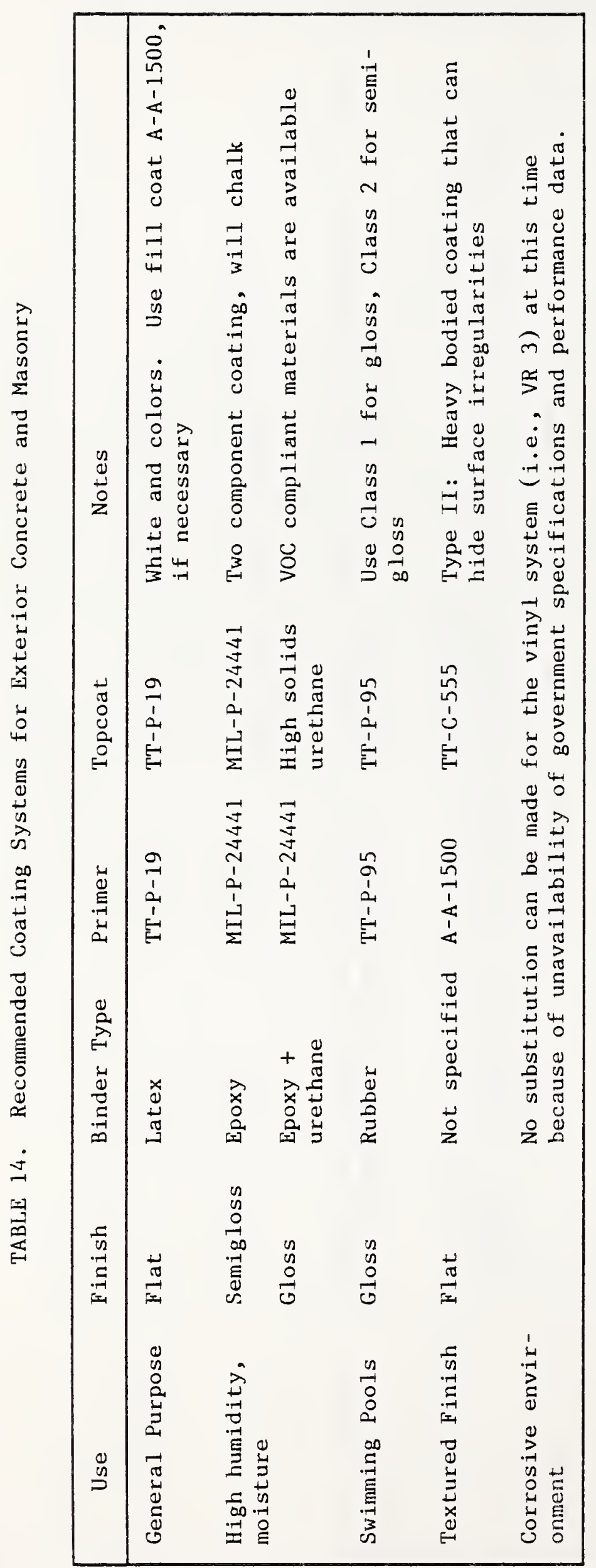




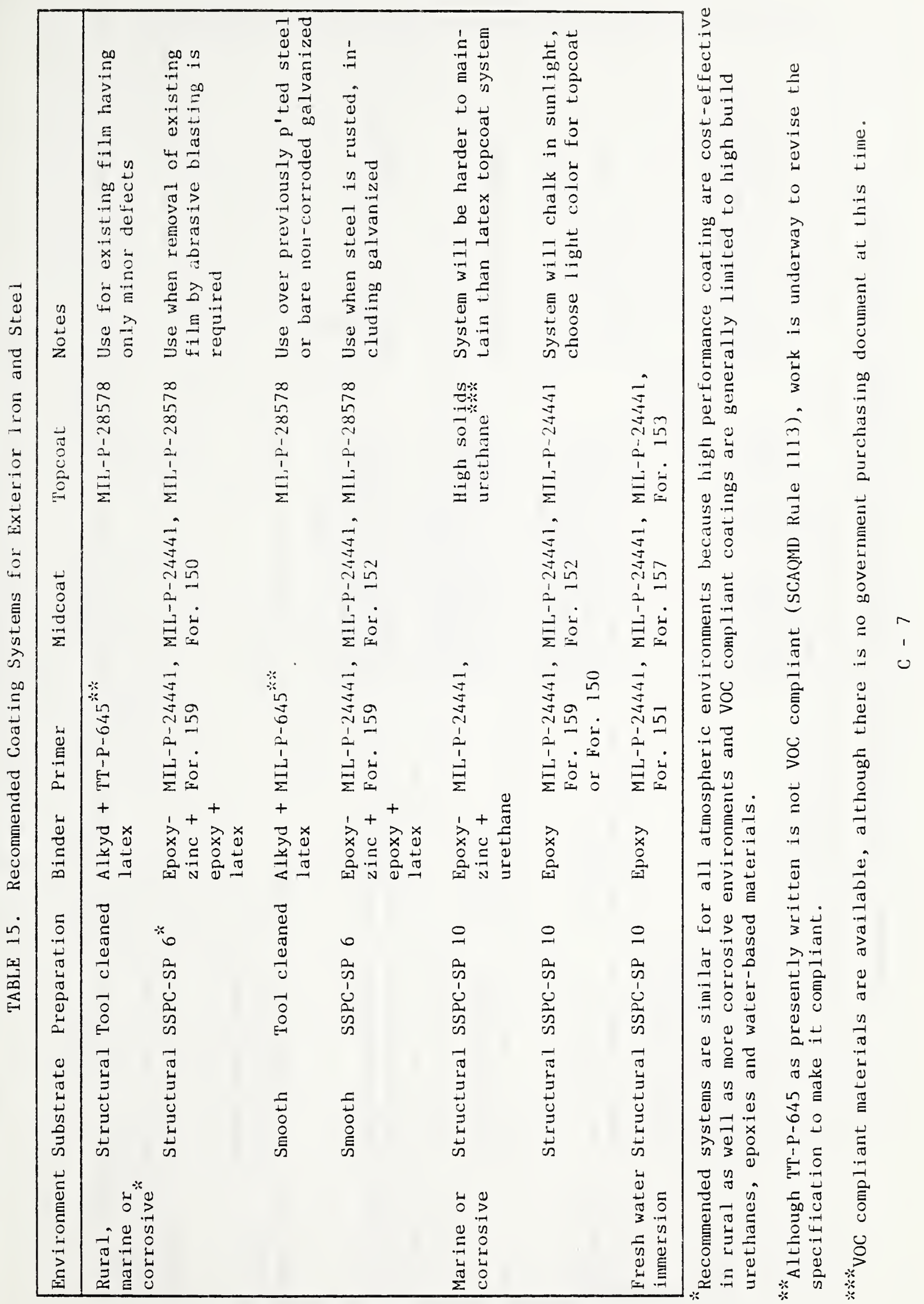




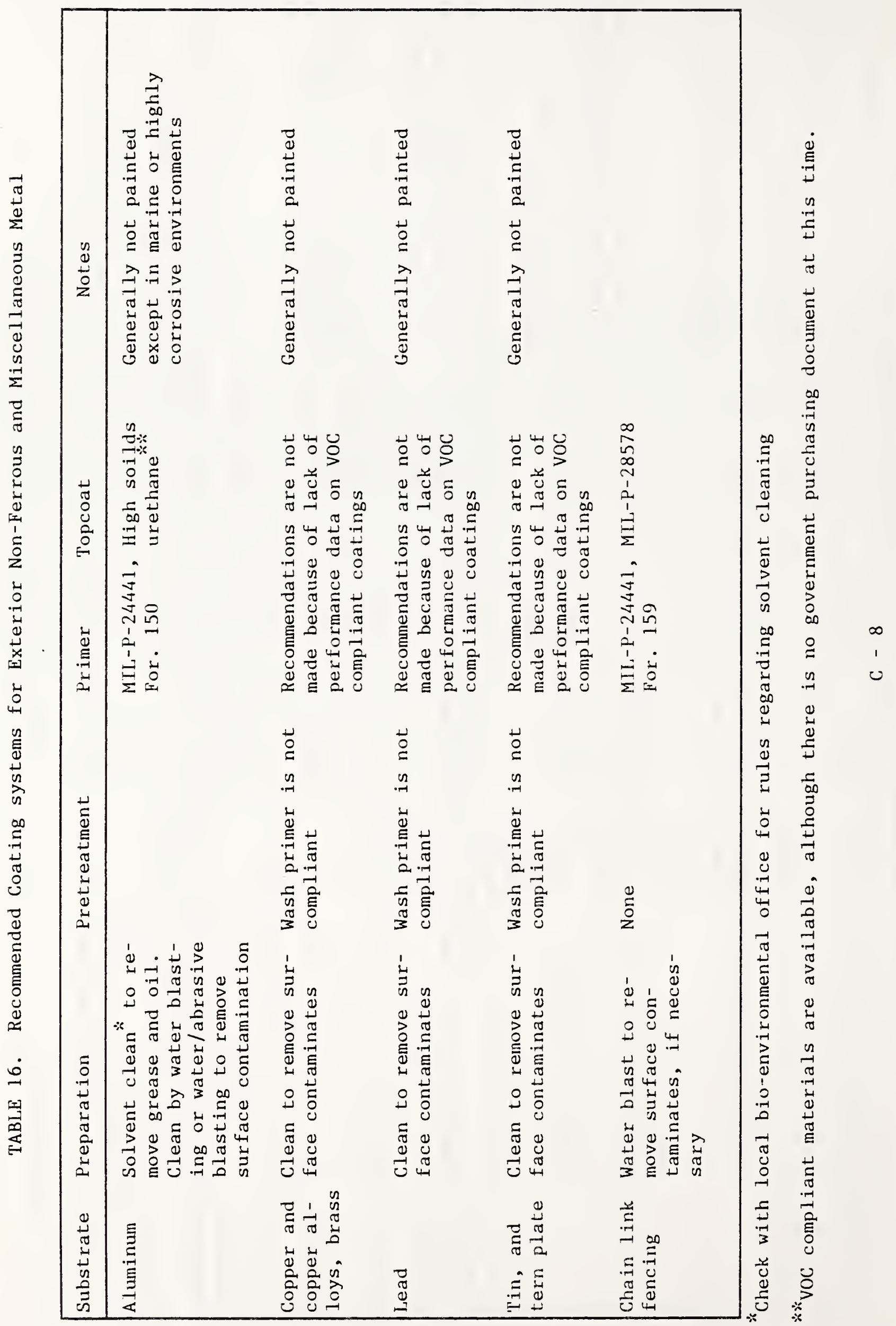




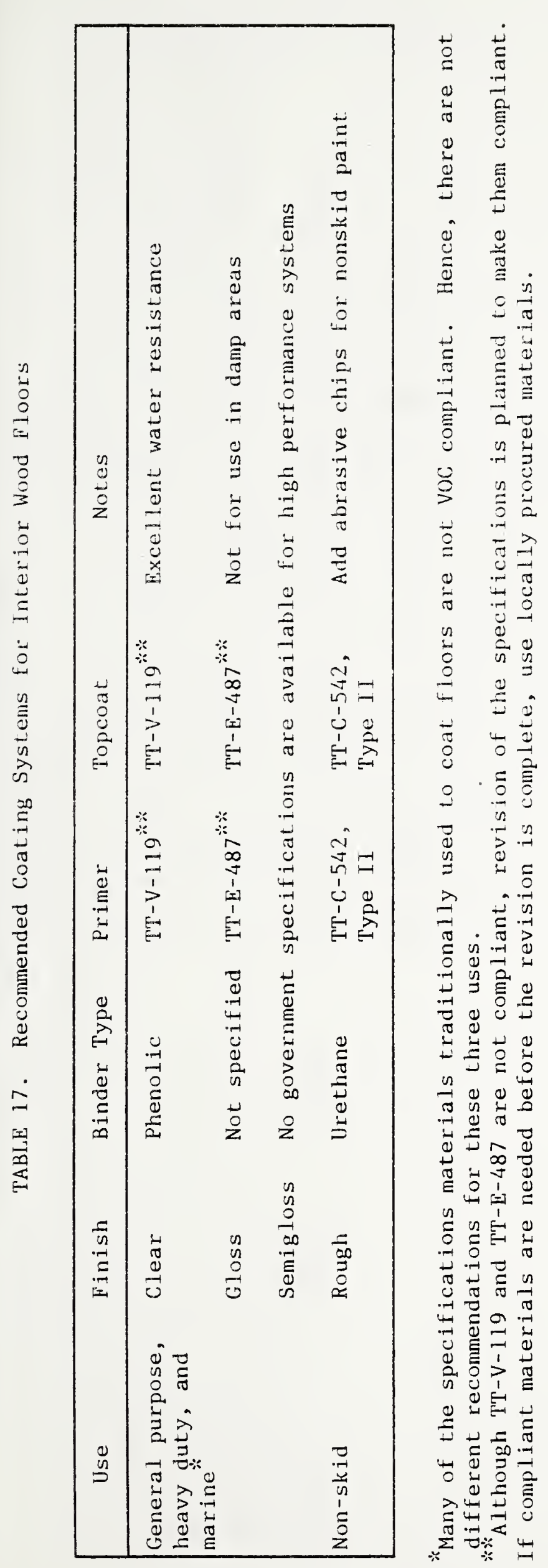




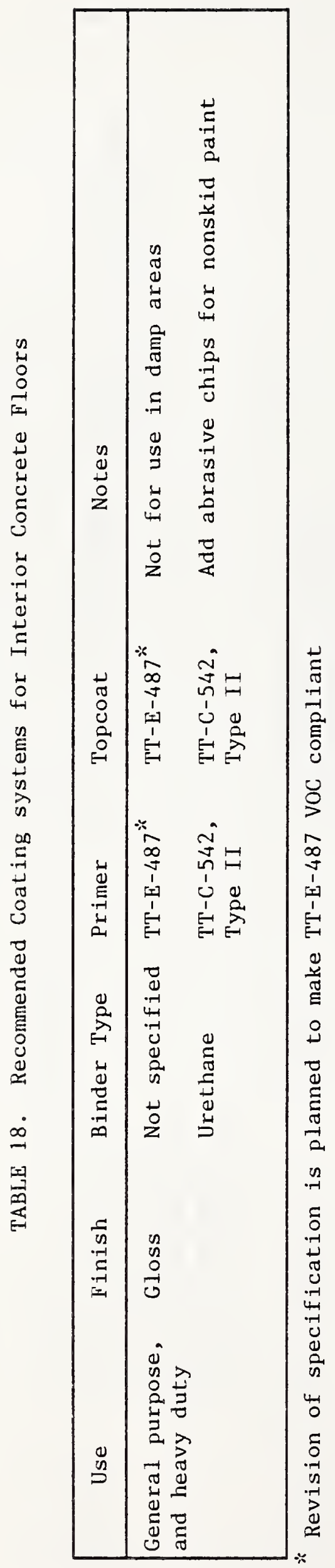




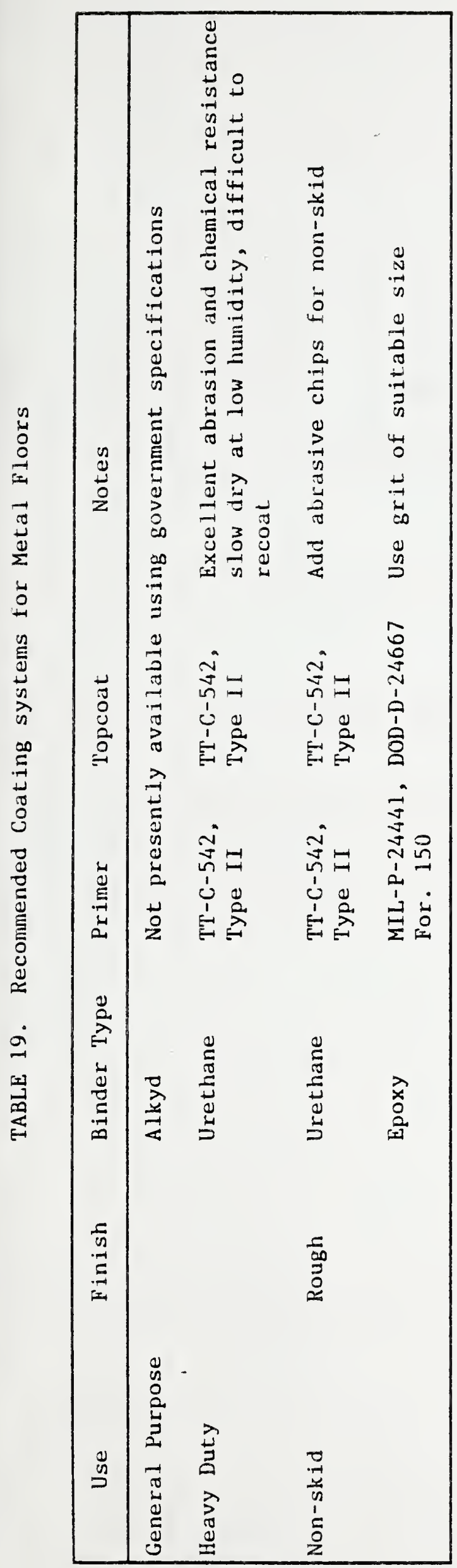


NBS. 114A (REV. 2.8C)

U.S. DEPT. OF COMM.

BIBLIOGRAPHIC DATA

SHEET (See instructions)

1. PUBLICATION OR REPORT NO.

NESIR $86-3499$
2. Performing Organ. Report Nof 3. Publication Date

FEBRUARY 1987

4. TITLE ANO SUBTITLE NBSIR 86-3499 (USAF)

Report on the Effect of Volatile Organic Content Regulations on the Selection and Use of Coatings Included in AFM 85-3 (Tri-Service Paints and Protective Coatings Manual)

5. AUTHOR(S)

Mary E. McKnight

6. PERFORMING ORGANIZATION (If joint or other than NBS, see instructions)

NATIOHAL BUREAU OF STANDARDS

DEPARTMENT OF COMMERCE

WASHINGTON, D.C. 20234

7. Contract/Grant No.

AFESC/F86-50

8. Type of Report \& Period Covered

NBSIR; 31 Sept. -31 Dec. 1986

9. SPONSORING ORGANIZATION NAME AND COMPLETE ADDRESS (Street, City, State, ZIP)

Aix Force Engineering and Service Center

Tynda11 AFB, FL 32403

10. SUPPLEMENTARY NOTES

[Document describes a computer program; SF-185. FiPS Software Summary, is attached.

11. ABSTRACT (A 200-word or less factual summary of most significant information. If document includes a significant bibliography or (iterature survey, mention it here)

The potential impact of the Federal Clean Air Act upon coating specifications recommended in AFM 85-3, Tri-Service Paints and Protective Coatings Manual, for the maintenance of Air Force facilities is assessed. The status of each specification is given, based, to the extent possible, upon a draft report prepared by Fort Belvoir's Research, Engineering and Development Center for the office of the Secretary of Defense. In addition, substitute coating specifications are recommended, when available.

12. KEY WORDS (Six to twelve entries; alphabetical order: capitalize only proper names, and separate key words by semicolons) coating; volatile organic content; Tri-Service Paints and protective Coatings Manual; AFM 85-3

13. AVAILABILITY

Unnlimited

For Official Distribution. Do Not Release to NTIS

$\square$ Order From Superintendent of Documents, U.S. Government Printing Office, Washington, D.C. 20402.

XXY Order From National Tecinnical Information Service (NTIS), Springfield, VA. 22161
14. NO. OF

PRINTED PAGES

63

15. Price

$\$ 13.95$ 
